\title{
Mediterranean Diet, Brain and Muscle: Olive Polyphenols and Resveratrol Protection in
}

\section{Neurodegenerative and Neuromuscular Disorders}

Carla Petrella $^{1 *}$, Maria Grazia Di Certo ${ }^{1}$, Francesca Gabanella ${ }^{1-2}$, Christian Barbato ${ }^{1}$, Flavio Maria $\mathrm{Ceci}^{3}$, Antonio Greco ${ }^{4}$, Massimo Ralli ${ }^{4}$, Antonella Polimeni ${ }^{5}$, Antonio Angeloni ${ }^{3}$, Cinzia Severini ${ }^{1}$, Mario Vitali ${ }^{6}$, Giampiero Ferraguti ${ }^{3}$, Mauro Ceccanti ${ }^{7}$, Marco Lucarelli ${ }^{3}$, Carola Severi ${ }^{8}$, Marco Fiore $^{1 *}$

1 - Institute of Biochemistry and Cell Biology, Section of Neurobiology, (IBBC-CNR), Rome, Italy

2 - Institute of Molecular Biology and Pathology (IBPM-CNR), Rome Italy

3 - Department of Experimental Medicine, Sapienza University of Rome, Rome, Italy

4 - Department of Sense Organs, Medical faculty, Sapienza University of Rome, Rome, Italy

5 - Department of Odontostomatological and Maxillofacial Sciences, Sapienza University of Rome, Italy

6 - ASUR Marche, AV4, Ancona, Italy

7 - Sitac, Societa' Italiana per lo Studio delle Patologie Alcool Derivate. Rome, Italy

8 - Dept of Translational and Precision Medicine, Sapienza University of Rome, Rome, Italy

*Correspondence:

Dr Marco Fiore, $\mathrm{PhD}$

Department of Sense Organs, Sapienza University Hospital, Rome Italy

Institute of Biochemistry and Cell Biology,

Section of Neurobiology, National Research Council (IBBC-CNR)

Via del Policlinico 162, 00185 Rome, Italy.

Email: marcofiore.roma@gmail.com

Dr Carla Petrella, PhD

Department of Sense Organs, Sapienza University Hospital, Rome Italy

Institute of Biochemistry and Cell Biology,

Section of Neurobiology, National Research Council (IBBC-CNR)

Via del Policlinico 162, 00185 Rome, Italy.

Email: carla.petrella@,cnr.it 


\begin{abstract}
The Mediterranean diet is worldwide recognized as a good prototype of nutrition, due to the conspicuous intake of olive oil, nuts, red wine, legumes, fruit, and vegetables, all fundamental elements rich in antioxidant substances and polyphenols. Polyphenols are a wide range of phytochemicals and/or synthetic chemical compounds, with proven beneficial properties for human health.

In the present review, we critically summarize the well-characterized antioxidant and antiinflammatory properties of polyphenols contained in the olives and extra virgin olive oil and of resveratrol, a non-flavonoid phenolic compound, providing a special focus on recent advances on the role of microbiota and microRNAs modulation as a valuable effect of these compounds. We also show the emerging importance of their consumption in the prevention and management of crucial neurodegenerative conditions (alcohol-related brain disorders and aging) and in neuromuscular disorders (Spinal Muscular Atrophy and Amyotrophic Lateral Sclerosis and Duchenne Muscular Dystrophy), where oxidative stress plays a predominant role.
\end{abstract}

Keywords: olive polyphenols; resveratrol; microbiota; miRNA; aging; alcohol-related brain disorders; SMA; ALS; DMD. 


\section{Abbreviations Used}

ALS - Amyotrophic Lateral Sclerosis

BDNF - Brain-derived neurotrophic factor

BMD - Becker Muscular Dystrophy

C9orf72 - Chromosome 9 Open Reading Frame 72

CRISPR - Clustered regularly interspaced short palindromic repeats

DMD - Duchenne Muscular Dystrophy

FALS - Familial form of ALS

FOXO3a - Forkhead transcriptional factor 3a

FUS - Fused in Sarcoma

HSF1 - Heat shock factor 1

lncRNAs - Long non-coding RNAs

MD - Muscular Dystrophy

MedDiet - Mediterranean Diet

miRNAs - MicroRNAs

mRNPs - mRNA-binding proteins

NADPH - Nicotinamide adenine dinucleotide phosphate

NGF - Nerve growth factor

Nox - NADPH oxidases

Nrf2 - Nuclear erythroid 2-related factor 2

PBMCs - Peripheral blood mononuclear cells

pri-miRNA - Primary miRNA

rAAV - Recombinant adeno-associated virus

RNAse - Ribonuclease

ROS - Reactive Oxygen Species

SALS - Sporadic ALS

siRNAs - Short interfering RNAs

SIRT1 - Sirtuin 1

SMA - Spinal Muscular Atrophy

SMN - Survival motor neuron

SOD1 - $\mathrm{Cu}-\mathrm{Zn}$ superoxide dismutase 1

TDP-43 - TAR DNA binding protein 43

TLR - Toll-like receptors 


\section{Introduction}

The idea that a proper nutrition could play a decisive role in promoting health is now increasingly consolidated. The Mediterranean diet (MedDiet) represents one of the most virtuous models of nutrition. This kind of diet was first described by Keys, who noted that Italians and Greeks showed a significantly lower mortality rate and incidence of cancer and cardiovascular diseases if compared to other countries $[1,2]$. The MedDiet indicates the dietary pattern, with some differences, of people living in Greece, Italy, and southern Europe, and is characterized by a great intake of olive oil, nuts, red wine, legumes, fruit, and vegetables, all fundamental elements rich in polyphenols. Adherence to the MedDiet includes also moderate consumption of fish, potatoes, eggs, and monthly consumption of red meat $[3,4]$. Furthermore, these populations follow social and cultural habits such as a widespread food practice, rest after meals, longer mealtimes, and regular physical activity [5,6]. Taken together, all these characteristics reduce the risk of developing cardiovascular diseases, hypertension, and neurological diseases [7-9]. Moreover, the MedDiet has shown positive results in controlling glycemia and reducing the risk of developing type 2 diabetes [10,11].

Polyphenols are a big and heterogeneous group of phytochemical or of chemical synthesis compounds, structurally characterized by the presence of one or more phenolic rings bounded to different structural units [12-14]. These compounds are classified, according to their structure, in phenolic acids, flavonoids, stilbenes, and lignans [15]. Polyphenols are naturally produced as secondary metabolites of plants and are generally involved in defense against herbivorous and pathogenic animals, mechanical support, protection against ultraviolet radiation, attracting pollinator insects, spreading fruits, and inhibiting plant growth competitors [15-17]. Some foods are rich in specific polyphenols, such as quercetin found in vegetables, fruit, cereals, legumes, wine, and tea [18-20]. Tyrosol, oleuropein and hydroxytyrosol are the main polyphenols present in black and green olive [18]. Olive oil is widely recognized as a symbol of the MedDiet. Olive oil is a product of the mechanical extraction of the olive fruit and is widely used as a source of vegetable oil [21]. Chemically, olive oil is composed of a lipid-soluble fraction, principally represented by 
monounsaturated oleic acid, and by a water-soluble fraction. Polyphenols are found in both fractions, aqueous and lipidic [22,23]. It is interesting to note that the olive leaf has a higher concentration of total polyphenols than the olive fruit [24]. Based on the definition of the European Union Regulations and according to their features, olive oils are commercially classified as extra virgin olive oil, virgin olive oil, and ordinary olive oil $[25,26]$. Compared to other olive oils, extra virgin olive oil has the highest quality, the best taste and aspect and the largest quantity of phenolic components, such as oleuropein and hydroxytyrosol, flavones, and lignans [27].

Resveratrol (3, 5, 4'- trihydroxy- trans-stilbene), is a polyphenolic compound of the stilbene family widely found in several plants, in fruits, such as grapes and berries, peanuts, tea, and in red wine [28]. Structurally, resveratrol has a low molecular weight and is formed by two phenol rings bounded together by a double styrene bond, and by three hydroxyl groups. The presence of a double-bound allows the existents of cis and trans isoforms. The last one is more stable and abundant in nature [29].

In the present work, we briefly summarize the well-characterized anti-oxidant and antiinflammatory properties of polyphenols contained in the olive oil and of resveratrol, with a special focus on the beneficial effect of these compounds in modulating intestinal microbiota and microRNAs. Then, we illustrate the emerging importance of these compounds in the prevention and management of well-known neurodegenerative conditions (alcohol-related brain disorders and aging) and in neuromuscular disorders (Spinal Muscular Atrophy/SMA and amyotrophic lateral sclerosis/ALS, Duchenne Muscular Dystrophy/DMD).

\section{Antioxidant and anti-inflammatory properties of olive oil-polyphenols and resveratrol}

Polyphenols are the main antioxidant compounds of our diet and are found in vegetables (broccoli, cabbage, and onion), extra-virgin olive oil, fruit (grapes, apples, pears, and cherries), legumes (soybean), cereals, chocolate, as well as in drinks such as red wine, coffee and tea [30-34]. Several scientific studies on olive oil showed its protective effects on health. In particular, polyphenolic compounds of olive oil, such as hydroxytyrosol, can neutralize free radicals and reactive oxygen/ 
nitrogen species as well as activate the endogenous antioxidant system $[35,36]$. Because of their antioxidant activity, polyphenols protect cells from damage and aging and, consequently, play a protective role in chronic diseases such as cancer, diabetes, obesity, neurodegeneration, and cardiovascular diseases [37-44].

The three hydroxyl groups of resveratrol, seem to be essential for its antioxidant activity as they are directly responsible of free radical scavenging and of metal chelation $[45,46]$. Several studies have demonstrated the antioxidant, anti-cancer, anti-inflammation, anti-aging, neuroprotective, and cardioprotective activity of resveratrol [21,47-51]. As an antioxidant molecule, resveratrol inhibits excessive Reactive Oxygen Species (ROS) production, lipid peroxidation, and aberrant mitochondrial network $[52,53]$. In epidermal keratinocytes, treatment with resveratrol increases the production of glutathione and decreases the levels of ROS [54]. Sgarbi et al., showed a lower mitochondria fragmentation and a higher conservation of the mitochondrial membrane potential in stressed fibroblasts when exposed to resveratrol [55]. Moreover, studies conducted in obese mice and diabetic rats under the administration of resveratrol revealed a normalization of stress conditions induced by hyperglycemia preventing hepatic steatosis [56,57]. In humans, resveratrol intake reduces oxidative stress in stress-related diseases. In type 2 diabetes, patients under resveratrol treatment improve insulin sensitivity, blood pressure and cardiovascular activity [58,59]. Furthermore, individuals with dyslipidemia or obesity show a reduction of plasma triglyceride levels when resveratrol is provided alone or mixed in a nutraceutical formula [60-62]. Taken together, these results indicate that resveratrol counteracts the increase in oxidative stress exerting a therapeutic effect.

Inflammation represents the main innate response of the immune system that fights against any kind of injury and infection [63-65]. Cytokines play a crucial role in this response; an uncorrected balance between pro-inflammatory and anti-inflammatory stimuli can lead to autoimmune diseases and chronic inflammatory conditions [66-69]. During the inflammatory response, the production of great quantities of ROS promotes additional oxidative stress perpetuating the inflammatory state [70]. Polyphenols may modulate the inflammation signaling with an antioxidant-based mechanism and by 
regulating the expression of inflammatory mediators. Toll-like receptors (TLR), a subfamily of pattern-recognition receptors, are primary immune sensors whose function is to activate intracellular signaling for the production of cytokines and chemokines that organize initial host defense against pathogens [71]. Resveratrol inhibits TLR4 signaling and the following transcription of IL-18 and IL$1 \beta[72,73]$. Resveratrol also promotes the nuclear translocation of the Nuclear Factor Erythroid 2Related Factor 2 (NRF2), which activates the transcription of antioxidant enzymes [74,75]. In vitro studies in human chondrocytes, using the flavanol Morin, showed an inhibition of IL-1 $\beta$ induced expression of cyclooxygenase-2 and matrix metalloproteinase [76,77]. In a rat model of osteoarthritis, the administration of curcumin and resveratrol suppressed the expression of IL-1 $\beta$, IL- 6 , and TNF- $\alpha$ $[78,79]$. Furthermore, polyphenols modulate the immune and inflammatory response by regulating the production of IL-10, an interleukin with anti-inflammatory activity [80,81]. Nutraceutical clinical studies in patients with type-2 diabetes, using a legume-based beans diet rich in kaempferol, showed an important decrease of inflammatory biomarkers like C- reactive protein, IL-6, and TNF- $\alpha$ [82]. Taken together, these data indicate that different kinds of polyphenols may regulate the inflammatory response.

\section{Olive polyphenols, resveratrol and alcohol drinking}

Acute, chronic, and prenatal alcohol exposure is associated with cognitive impairment and various forms of dementia, as well as with brain damage, liver diseases, cancer, stroke, and injury [83-90]. Ethanol affects organs by inducing cell death and by decreasing cell proliferation [91-93]. The mechanism underlying the neurotoxicity of ethanol is not yet clearly known. Different studies have hypothesized that alcohol consumption may alter neurotrophins production, the neuronal growth factors involved in cognitive, learning, and memory activity [94-96]. Nerve growth factor (NGF) and brain-derived neurotrophic factor (BDNF) are the best-studied neurotrophins in the physiopathology of alcohol use disorders [94,97-99]. Furthermore, they play a crucial role in survival, growth, and differentiation of neuronal cells [100-103]. 
Oxidative stress is the main mechanism responsible for alcohol induced damage. Alcohol is mainly metabolized in the liver where initially it is oxidized by alcohol dehydrogenase to acetaldehyde, which is then metabolized to acetate [104,105]. Moreover, chronic alcohol consumption activates cytochrome P450 2E1 which converts alcohol to acetaldehyde in the presence of oxygen and NADPH [106]. Acetaldehyde is highly toxic as it alters mitochondrial structure and functions and consequently increases ROS production and decreases the synthesis of ATP [107].

Therapies to reduce oxidative stress can contain the damage caused by alcohol abuse, for this reason polyphenols are used as therapeutic options against inflammatory and oxidative related diseases [108,109]. Intraperitoneal injections of a mixture of pomace polyphenols increased NGF and BDNF levels in the olfactory bulbs and in the limbic system in a mouse model $[110,111]$. However, a toxic effect in a different study was observed using a blend of olive leaf polyphenols containing mostly oleuropein [112]. A recent study, demonstrated for the first time that administration of a solution enriched in polyphenols prevented ethanol-induced oxidative damage in alcohol addicted individuals [113]. In particular, this polyphenol's blend, rich in hydroxytyrosol and its derivatives, reduced serum-free oxygen radicals without affecting the free oxygen radicals defense [98]. Ceccanti et al. showed that polyphenol supplementation, predominantly composed by hydroxytyrosol, counteracted the expected increase in BDNF on day 3 of administration in men affected by AUD during withdrawal [114]. These data indicate how serum neurotrophins levels are useful to characterize patients with alcohol dependence to improve their clinical management.

In alcoholic adult male mice, the intake of resveratrol actively counterbalances serum ROS formation caused by chronic alcohol consumption and also modulates BDNF level increase in the liver, one of main organs involved in the damage induced by alcohol [115]. In a mouse model of Fetal Alcohol Spectrum Disorders [96,116,117], red wine administration during pregnancy elicited only minor changes in cognition and in NGF/BDNF levels with respect to the sole alcohol administration; this mostly due to the antioxidant and neuroprotective abilities of wine polyphenols $[21,90,93,99,118,119]$. 


\section{Polyphenols and microbiota}

It is now well established that the microbiota has a crucial role in maintaining a healthy state and at the same time is known that many factors can influence it: diet and lifestyle for first. Indeed, the role that compounds such as polyphenols plays towards the human bacterial component is instead less explored, despite the fact that this healthy molecules can be supplemented in normal nutrition and, with ad hoc formulations, in certain pathological conditions [120] .

Recently, emerging evidence shows that beneficial effects obtained from polyphenol supplementation might be mediated by the intestinal microbiota. In a recent meta-analysis conducted by Ma and colleagues [121], emerged that polyphenols can impact the intestinal microbiome. In particular, the bacterial component most associated with beneficial effects (Lactobacillus and Bifidobacterium) results positively modulated, displaying also a counteracting role against potentially pathogenic species such as Clostridium. Due to their heterogeneity, however, these results are not always consistent or conclusive. Moreover, remains to be clarified how bacterial modulation occurs.

Nevertheless, evaluating the effects of the polyphenols contained in some foods (for example tea, apples, wine, coffee, etc.) compared to a placebo, in particular on the consistency of bacterial intestinal flora, it was found that the fecal content of Lactobacillus and Bifidobacterium was significantly increased, $220 \%$ and 56\% respectively. Conversely, no significant effect was evidenced on Eubacterium or Bacteroides. Moreover, these results are not affected by the origin of polyphenols. Food-dependent alterations have however been recorded for the expression of Atopobium: variations in the dose of polyphenols do not seem to influence the concentration of some strains (Prevotella and Atopobium) while, on the other hand, a significant increase in Bacteroides, as well as in Enterococcus and Enterobacteria was recorded.

According to in vivo studies focusing on the most altered species (Lactobacillus, Bifidobacterium, Clostridium) it emerged that blueberries and red wine potentiate the expression of Lactobacillus; in vitro studies instead show a higher impact of coffee and potatoes. The dose of polyphenols used in 
clinical studies is extremely variable $(6.4-2.364 \mathrm{mg} / \mathrm{d})$; the intermediate dose $(396 \mathrm{mg} / \mathrm{d})$ seems to have the most significant effects on Lactobacillus. At higher doses, bacterial proliferation seems to decrease. A wide range of doses were also observed in vitro $(0.079-1886 \mathrm{mg} / \mathrm{L})$; the best results were attributed to doses $<62.5 \mathrm{mg} / \mathrm{L}$. Polyphenols contained in red apple, at a dose of $540 \mathrm{mg} / \mathrm{die}$, showed in vivo the greatest effects on the abundance of Bifidobacterium, followed by those present in red wine. The greatest impact in vitro (concentration of $23 \mathrm{mg} / \mathrm{L}$ ) was instead recorded by grape seeds and potatoes. Tea polyphenols, followed by those of apple, showed the best activity in decreasing the expression of pathogenic species associated in vivo with Clostridium. A dose of polyphenols equal to $554-593 \mathrm{mg} / \mathrm{die}$, regardless of the source, promotes the abundance of Bacteroides.

In conclusion, the effect of polyphenols on the microbiota seems to depend on the source, but mainly on their concentration. The intake of polyphenols contained in grapes and red wine can positively modulate human intestinal microbiota, favoring host healthy state. Available data are so far mostly obtained from preclinical experimentation. Clinical studies are not yet sufficient and require further confirmation, although promising and deserving of further investigation. Studies that analyze the presence, in humans, of polyphenols metabolites (whose role is fundamental in explicating their beneficial effects) are quite interesting; most of the dietary polyphenols, especially those assumed by grapes and red wine, reache the colon almost intact, where they are degraded into simple phenolic acids by the bacterial component.

What emerges from a review of the literature [122] is that the modulation of the endogenous microbial component exerted by polyphenols (specifically grapes, red wine or their extracts), is reflected in a modification of their metabolism by specific bacteria. In particular, the study by QuiepoOrtuno et al. [123] showed that: i) the consumption of red wine may increase Enterococcus, Prevotella, Bifobacterium, Bacteroides uniformis, Eggerthella lenta, and the Blautia coccoidesEubacterium rectale groups, but decreases the presence of Actinobacteria and, to a lesser extent, Clostridium spp. and C. histolyticum; ii) interestingly, the consumption of de-alcoholic red wine promotes the growth of Fusobacteria as Firmicutes and the Blautia coccoides-Eubacterium rectale 
groups as well as Enterococcus, while it reduces Actinobacteria as Bifidobacterium and Eggerthella lenta.

Concerning the effects of wine polyphenols on microbiota-mediated phenolic metabolites, it emerges that an increase in metabolites of resveratrol was recorded in the urine and blood [123-126]. A similar trend was also demonstrated following the consumption of de-alcoholic red wine, suggesting that the alcohol component does not affect the production of phenolic metabolites by the intestinal microbiota.

In conclusion, it seems clear that the intake of polyphenols modifies the intestinal microbiota both in qualitative and quantitative terms, also increasing bacterial production of phenolic metabolites. The small number of clinical studies, according to the authors, however, underlines the need for further investigations before certainly stating the benefits of polyphenols on the human bacterial component.

\section{Polyphenols: a new fuel for MicroRNAs?}

Several observations are reported on transcriptomics, diet and molecular mechanism driving the epigenomics interplay between DNA methylation, histone modifications and non-coding RNAs $[127,128]$. Effects of polyphenols on human health are mediated by pleiotropic actions including modulation of non-coding RNAs, a recent discovered class of molecules playing a vital role in maintaining genomic stability by regulating gene expression [129]. In particular, several experimental works evidenced a potential role that non-coding RNAs-related regulatory processes contribute to the pathogenesis of various aging-related diseases, such as Alzheimer's disease, Parkinson and neuromuscular disorders [129].

Among non-coding RNAs, there are siRNAs, microRNAs (miRNAs) and long non-coding RNAs (lncRNAs). They play a central role in maintaining an healthy state in organisms; moreover, several works report a description of their biological functions in aging [130,131]. Briefly, we reported 
emerging literature concerning diet, polyphenols and microRNAs and their potential involvement in aging and aging-related diseases.

MiRNAs are small noncoding regulatory RNAs, single-stranded RNAs of about 22 nucleotides, which tune gene expression at the post-transcriptional level by target mRNAs degradation or inhibition of their translation. The first step consists in miRNA transcription by RNA polymerase II (Pol II), generating a primary miRNA (pri-miRNA) transcript, spanning in length from 100 to 1000 nucleotides and containing a 60-80 nucleotides stem-loop structure. In the nucleus, the ribonuclease III (RNAse III) -like enzyme Drosha and the RNA-binding protein DGCR8/Pasha, process primiRNA in a hairpin intermediate called pre-miRNA exported in the cytoplasm. After processing by RNase III enzyme Dicer, which cuts out the loop region of the hairpin, a 18- to 24-nucleotide mature miRNA is released. MiRNA is then incorporated into the RISC complex which contains Ago2, a key component of an Argonaute protein family. Ago2 directly binds the miRNA generating the effector complex of the miRNA pathway. MiRNA drives endogenous gene expression inhibiting the target mRNA translation by an imperfect pairing with 3'UTRs of the mRNA targets [132]. Otherwise, when the miRNA binds to mRNA with perfect complementarity, cleavage of mRNA is induced. To date more than 1000 miRNAs have been found in the human genome and it is believed that they can tune more than one third of the mammalian genes.

To understand the relationship between polyphenols and microRNAs and their potential involvement in aging related diseases, it is relevant to consider two specific aspects: circulating miRNAs and food miRNAs. MiRNAs can be found in saliva, plasma, urine and cerebrospinal fluid and other body fluids. MiRNAs are suspended in biological fluids complexed with exosomes, lipoproteins, and RNA-binding protein due to the necessity of their protection from degradation. For these reasons, circulating microRNAs can be considered strategic biomarkers of health, disease, and nutritional status. Liquid biopsies represent an innovative and powerful diagnostic tool to discover changes in microRNA profiles [133]. On the other hand, nutrients in foods, such as fatty acids, vitamins and derivatives, amino acids and polyphenols can modulate miRNA expression [134]. 
Putting together that miRNAs expression can be conditioned by nutrient as polyphenols and that miRNAs have a spreading capability through biological fluids, it is conceivable to think that many metabolic pathways, as cholesterol metabolism (and consequently cardiovascular diseases), insulin sensitivity (diabetes), aging and inflammation might be regulated by molecular determinants belonging to non-coding RNAs and antioxidants families [135]. Among polyphenols, flavonoids in particular show beneficial cognitive effects by reversing age-related neurodegenerative declines [136].

MicroRNAs can modulate biological processes related to aging, targeting genes belonging to the nutrient-sensing pathways which expression could be affected by aging. Cognitive decline is linked to age-related neurodegenerative pathologies as Alzheimer's disease, in which a putative association with nutrient-sensing pathways, influenced by polyphenols, is suggested. Are microRNAs players of this pathway? The mechanisms by which aging/neurodegenerative processes modify microRNA expression is still unknown, and the experimental work is to its infancy. Many experimental works were performed on miRNAs expression profile in age related-diseases, especially on liquid biopsies, evidencing that there is a relationship between miRNAs, Alzheimer disease gene targets, neuronal pathways, and intracellular and extra-cellular miRNAs gene expression profiles [137]. Serna et al. studied microRNA expression profiles in more than thirty old subjects ( 20 centenarians and 16 octogenarians) and young persons in peripheral blood mononuclear cells (PBMCs) [138], showing a linear miRNAs decrease with aging. Surprisingly, centenarians overexpressed these miRNAs at higher levels with respect to octogenarians suggesting that extraordinary aging is sustained by elevated levels of miRNAs. These data were also confirmed by a transcriptome analysis from centenarians versus octogenarians, confirming distinct gene expression patterns in humans with exceptional longevity [139]. Besides, ElSharawy et al. explored for the first time the miRNA signature of human longevity, showing 16 miRNAs up-regulated and 64 down-regulated in blood samples from the long-lived individuals (centenarians and nonagenarians) with respect to younger individuals [140]. MiRNA microarray expression data revealed that clustered down-regulated aging- 
associated miRNAs appear to be associated more often with a disease context than those up-regulated. In addition, a large part of the differentially regulated miRNAs described appears with a divergent pattern of expression in main age-related diseases, suggesting that miRNome does not change linearly along with aging. In order to explain overexpression of specific miRNAs at higher levels in centenarians with respect to octogenarians, the expression of miRNA biogenesis machinery during ordinary aging was recently explored [141]. The transcriptome profile of RNA Pol II, Drosha, Exportin5 and DICER, the main proteins involved in miRNA maturation, was evaluated in PBMCs; a downregulation in octogenarians and an increase in young and in centenarians was observed, confirming that centenarians reflect a miRNA processing machinery activity similar to that found in young individuals [141]. In this context, studies on the role of polyphenols on miRNA biogenesis machinery during aging (from young to centenarian people), on the regulation of miRNome and on the more appropriate nutrients for a healthy aging are mandatory.

All these studies show that aging significantly modulates the expression of microRNAs. However, the significance of age-related microRNA modulation is under investigation and the study of the role of microRNAs in aging is still at the beginning, as described in recent works on microRNAs in aging processes [142]. In conclusion, the axis polyphenols-microRNAs-aging and age-associated diseases represents a newborn research field. There are many aspects to consider properly to disclose the cellular, molecular, and biochemical links. Several reports on animal models showed that compounds assumed with food, including polyphenols, may influence the microRNA expression and regulate target pathways [143-145]. To date, studies and clinical trials in humans on the influence of nutrient components on microRNA expression or profiles are limited [127,146-148], and should plan -omics approaches and standardized techniques to reduce the high variability in response of recruited subjects and of environmental conditions. Lastly, an unsolved question is if the circulating miRNAs are partially derived from foods, if they can cross the digestive barrier, pass in blood circulatory torrent of humans preserving their modulatory capacity on metabolic pathways $[149,150]$. In this regard, a very recent study evidenced postprandial modification of plasma microRNA levels after 
intake of extra virgin olive oil. Among the miRNAs mainly modulated, analyzed by real-time quantitative PCR, plasma let-7e-5p levels resulted reduced, indicating that such miRNAs could potentially represent targets of modification either by monounsaturated fatty acids or olive oil polyphenols introduced with the diet. Even if this study was devoted to cardiovascular diseases, it shows that $i$ ) dietary intake modulates circulating miRNAs; ii) circulating miRNAs become 'nutrient's messengers and iii) miRNAs act on their specific mRNA targets tuning metabolic pathways, potentially involved and/or associated with aging processes or age-associated diseases [151]. A future challenge of studies will be to determine the most promising dietary interventions to promote healthy aging and prevent cognitive decline and neurodegenerative diseases.

\section{Resveratrol and neuromuscular diseases}

Neuromuscular diseases are a heterogeneous group of disorders that directly affects muscle function and structure or, indirectly, impairs muscle control by motor neurons. Because of an altered muscle function, patients develop weakness that can be progressive and lead to paralysis and death. Spinal muscular atrophy (SMA) and amyotrophic lateral sclerosis (ALS) are two disorders in which muscle impairment is primarily caused by the degeneration of motor neurons [152].

Several lines of evidence suggest that polyphenols contained in fruits and vegetables exhibit a protective activity in neuromuscular disorders. Among them, resveratrol seems to be a good candidate for this purpose, due to its neuroprotective properties [153]. Different signaling pathways involved in inflammation, oxidative stress and neuronal differentiation have been reported as targets of resveratrol demonstrating its usefulness in multisystem disorders like SMA and ALS.

\section{Resveratrol and Spinal Muscular Atrophy}

SMA is a severe autosomal recessive disorder, characterized by the selective degeneration of the motoneurons, in the anterior horn of the spinal cord. This disease is the most common genetic cause of infant mortality with an estimated incidence of 1 in 6,000 to 10,000 live births. SMA 
pathophysiology includes progressive proximal muscle atrophy leading to paralysis and, in the most severe cases, respiratory distress. SMA is caused by low levels of the survival motor neuron (SMN) protein, due to deletions/mutations in the SMN1 gene [154-157]. SMN is highly conserved throughout evolution and its function is essential for cell viability. SMN works as a master assembler of RNA-protein complexes, and its function is required for key cellular processes, including transcription, pre-mRNA splicing, and ribosome biogenesis. The best-characterized function of SMN is the assembly of the spliceosomal small nuclear ribonucleoproteins, in association with a multiprotein complex, comprising Unrip and seven Gemin proteins (Gemin 2-8) [158,159]. Moreover, SMN also associates with several mRNA-binding proteins (mRNPs), such FMRP, FUS, KHSRP, HuD, and it traffics with $\beta$-actin mRNA in neuronal processes, suggesting a possible role of SMN in mRNA transport and/or local translation [160-168].

In humans, there is a duplicated form of SMN1 gene, named SMN2. The SMN2 gene differs from SMN1 by only five nucleotides. As consequence, SMN2 produces a reduced amount of full-length SMN protein, which cannot fully compensate for the absence of SMN1. Although SMN1 loss is essential to SMA pathology, the number of SMN2 copies determines its severity [169].

Currently, therapeutic strategies in SMA can be subdivided into SMN-dependent and SMNindependent approaches, which aim to increase SMN levels by favoring the inclusion of exon 7 in SMN2 transcript or replacing SMN1 gene or targeting SMN-independent factors. Of note, it has been demonstrated that resveratrol may modulate gene expression and alternative splicing of mRNA likely by directly binding to DNA and RNA [170]. In this regard, Sakla and Lorsorn tested the effects of resveratrol and other polyphenol compounds on SMN2 exon 7 inclusion. They observed an increased production of full-length SMN RNA and an augmented concentration of protein as well as the formation of SMN-containing nuclear gems in SMA patient fibroblasts treated with these compounds [171].

Moreover, resveratrol can alter the alternative splicing of mRNA transcripts by affecting the levels of specific splicing factors. The level of ASF/SF2, hnRNPA1 and HuR protein were increased but 
not the level of other splicing factors like RBM4, PTBP1 and U2AF35. ASF/SF2 and hnRNPA1are both involved in exon 7 splicing of SMN2, suggesting that resveratrol acts in a specific manner for some but not all splicing events [172].

\section{Resveratrol and Amyotrophic Lateral Sclerosis}

ALS is a progressive and fatal neurodegenerative disease, characterized by a selective loss of upper and lower motor neurons of the brainstem and spinal cord [173-175]. Clinical manifestations of ALS include weakness, muscle denervation and atrophy, progressive paralysis of all muscles that leads to respiratory failure and death [176-179]. The survival rate is estimated at about 3-5 years after the onset of symptoms [180-184]. Two ALS forms have been identified: sporadic ALS and familial ALS. The majority of ALS cases are sporadic (SALS) with no known genetic component, while $10 \%$ of them are familial forms (FALS) with a positive familial history and a genetic component $[185,186]$. Currently, over 25 genes have been identified as possible causes of onset for ALS [187]. The most common and most well-characterized mutations contributing to ALS pathology are found in the following genes: $\mathrm{Cu}-\mathrm{Zn}$ superoxide dismutase 1 (SOD1), Fused in Sarcoma (FUS), TAR DNA binding protein 43 (TDP-43) and a hexanucleotide expansion repeat in Chromosome 9 Open Reading Frame 72 (C9orf72) [188]. To investigate the molecular pathway affected in ALS pathology several in vivo and in vitro models of disease have been developed $[189,190]$. The results obtained from the analysis of these models highlighted different cellular and molecular mechanisms involved in ALS pathogenesis including mitochondrial dysfunction, ROS-associated oxidative stress, protein misfolding and aggregation, autophagy, apoptosis, nuclear-cytoplasmic transport, glutamatemediated excitotoxicity and altered RNA metabolism and/or processing [191-195].

Although different cellular pathways are involved in ALS, the progression of the disease leads inexorably to motor neuron death. Currently, no effective treatments are available for ALS. Therapy is limited only to symptomatic and palliative treatments. Edaravone and riluzole are the only approved pharmacological treatments that can improve the survival rate by $2-3$ months $[196,197]$. In 
this context, the antioxidant properties of resveratrol could positively target molecular mechanisms affecting mitochondrial biogenesis and autophagy involved in ALS pathology.

Resveratrol may delay the onset of ALS, increasing the survival and preserving the function of spinal motor neurons $[198,199]$. Mitochondrial impairment and ROS production may be reduced by treatment with resveratrol. In this regard, resveratrol protects against mitochondrial fragmentation by the activation of PGC1a mediated by the interaction between resveratrol and "silent information regulator factor 2-related enzyme 1" (sirtuin1 or SIRT1). Moreover, the interaction of resveratrol with SOD1 protein [200-202] has positive effects on the up-regulation of SIRT1 expression in the mutant hSOD1-G93A-bearing motor neuron-like cell culture model of ALS [203]. Toxic effects from the accumulation of misfolded SOD1 aggregates are decreased by activation of SIRT1 by resveratrol administration. In detail, resveratrol activates SIRT1, which in turn deacetylases HSF1, inducing the transcription of hsp70 and hsp25 and increasing motor neuron survival [204].

Inhibitory effects of resveratrol on apoptosis were also observed. SIRT1 resveratrol-activated mediates deacetylation and inhibition of p53. Inhibited p53 is unable to induce the expression of the pro-apoptotic protein Bax [205]. Recently Yun et al. showed that down-regulation of AMPK/SIRT1 signaling in bone marrow mesenchymal stem cells from ALS patients can be recovered by resveratrol administration [206]. Finally, resveratrol shows neuroprotection effects against glutamate toxicity in neuronal cultures and prevents the accumulation of high calcium concentrations [207,208].

\section{Resveratrol and Muscular Dystrophies}

Muscular dystrophies (MDs) include over 30 genetic diseases characterized by progressive loss of muscle function. The clinical phenotype of MDs is very heterogeneous for severity, age of onset, and primarily affected muscle types. Patients with MDs develop severe disabilities including loss of ambulation, respiratory and cardiac insufficiency [209-211]. Duchenne Muscular Dystrophy (DMD) is the most common MD. DMD is a X-linked recessive disease with a high incidence in the male population (1/3500) [212,213]. Mutations in the gene encoding dystrophin cause DMD as well as the 
milder form Becker Muscular Dystrophy (BMD) [214]. Dystrophin is a cytoskeletal protein, which plays a major structural role in muscle, providing proper plasticity of the plasma membrane (sarcolemma) during muscle contraction [213]. Dystrophin-deficient skeletal muscles exhibit typical parameters of damage susceptibility such as an altered architecture, inflammation, and fibrosis. Injured muscles undergo a reduced regenerative capacity, progressive muscle weakness, and atrophy. Individuals with DMD manifest gait and posture changes early, with loss of ambulation at the age of 8-12 [215]. At the cardiac level, DMD is characterized by a dilated cardiomyopathy and/or arrhythmias progressively increasing with age [216,217]. Consequently, heart failure is a leading cause of death in DMD. Although the underlying pathogenesis is well known and several clinical trials are in progress, DMD still lacks an effective cure and, so far, corticosteroids remain the only treatment.

The therapeutic strategies designed to treat DMD can be divided into three categories: gene therapy, cell therapy and pharmacological treatment [218]. Overall, therapeutic interventions aim to replace/repair the genetic defect or modify expression levels of disease-related genes. Noteworthy, the size of the dystrophin gene, the largest known [219], has made particularly tedious the development of gene therapies, strongly delaying their clinical translation. Pharmacological therapies instead aim to counteract or mitigate the pathogenetic mechanisms that sustain the progression of the disease $[220,221]$. Indeed, the searching for synthetic or natural molecules able to prevent muscle waste, possibly by a synergistic association with gene therapies, become a crucial objective. Several findings converge to the notion that oxidative stress may be a critical component in DMD pathogenesis [222,223]. A study monitoring two age classes of DMD patients revealed that a dysregulated enzymatic antioxidant response at the muscular level correlates with the severity of pathology [224]. To counteract oxidative stress, dystrophin-deficient myofibers activate NRF2 that in turn promotes a chronic inflammation, which exacerbates the dystrophic phenotype [224]. Due to its ability to target metabolic/oxidative pathways, resveratrol appears a promising therapeutic tool for the treatment of muscular dystrophies. In mdx mice, an animal model of DMD, resveratrol preserves 
cardiac function, counteracting cardiac hypertrophy and fibrosis. Indeed, diet supplementation with resveratrol for 32 weeks causes a significant reduction of oxidative damage as well as inflammationrelated genes in the muscles of mdx mice [225,226]. A mechanism by which resveratrol reduces muscular damage relies on the activation of SIRT1 [227]. SIRT1 is a NAD+-dependent protein deacetylase, which plays a key role in metabolism, mitochondrial pathways, and inflammation [226]. Downstream consequences of SIRT1 pathway activation enable cells to establish efficient oxidative stress response. Indeed, resveratrol significantly reduces oxidative stress markers in dystrophindeficient muscles [226]. Notably, in mdx mice resveratrol significantly reduces expression levels of NADPH oxidases (Nox) and their subunits including Nox4, which is a major source of oxidative stress implicated in several diseases [225]. Furthermore, up-regulation of SIRT1 in the skeletal muscle of mdx mice improves their exercise performance during the treadmill test [228]. Ubiquitindependent degradation of the transcriptional co-activator p300 represents a further cardioprotective mechanism of resveratrol [229]. p300 protein is an important player in cardiac development and its overexpression contributes to cardiac hypertrophy. Indeed, expression levels of p300 protein appear dysregulated in DMD patients [229]. Interestingly, resveratrol acts as a strong inducer of autophagy as well as mitochondrial autophagy (mitophagy) [230]. In $\mathrm{C}_{2} \mathrm{C}_{12}$ myoblasts, mitophagy occurring upon resveratrol treatment enables cells to remove aberrant mitochondria and reduces ROS levels [230]. Furthermore, in mdx mice resveratrol switches on autophagy-related genes that are transactivated by the Forkhead transcriptional factor 3a (FOXO3a) [231]. Finally, resveratrol corrects dystrophic phenotype by reducing inflammation-related genes and up-regulating utrophin-encoding transcripts [232]. Collectively, these findings confirm that resveratrol may provide beneficial effects for progressive dystrophic pathologies. The idea is that resveratrol could be considered in strategies that combine multiple approaches into a single clinical trial, in order to achieve more effective treatments for MDs. 


\section{Conclusion}

Nutrition plays a primary role in the preservation of human health. The Mediterranean Diet is an important ally in the prevention of various chronic diseases including those related to neurodegeneration. The presence of various compounds with beneficial properties makes this diet a powerful tool for this purpose. Obviously, the quantities of these substances taken daily by diet are not enough to obtain beneficial effects especially in pathological conditions. For this reason, "therapeutic" concentrations of polyphenols can be achieved only supplementing the normal diet. As summarized in this review (Figure 1), polyphenols derived from olives and resveratrol could be an effective treatment in those pathological conditions where oxidative stress and inflammation play a crucial role. In this sense, the use of these complements as adjuvants of standard therapies could allow the reduction of the dosages of conventionally used medications, enhancing therapeutic effects and at the same time drastically reducing drugs side effects, often linked to the duration of the therapy. An increase in clinical trials to confirm the validity of the polyphenolic supplementation efficacy is certainly mandatory; for what is emerged so far, their use promises positive outcomes in different pathological conditions. 


\section{ACKNOWLEDGEMENTS}

Authors thank IBBC-CNR and Sapienza University of Rome for supporting this work.

\section{DISCLAIMER}

Nothing to disclose

\section{CONFLICTS OF INTEREST}

All the authors do declare no conflicts of interest.

\section{AUTHOR CONTRIBUTION}

$\mathrm{CP}, \mathrm{MGDC}, \mathrm{CB}, \mathrm{FG}, \mathrm{FMC}, \mathrm{GP}, \mathrm{MC}, \mathrm{AG}, \mathrm{MV}, \mathrm{CaS}, \mathrm{AP}$ and MF were responsible for the review concept and design.

$\mathrm{CP}, \mathrm{MR}, \mathrm{AA}, \mathrm{CiS}, \mathrm{CaS}$ and $\mathrm{MF}$ were responsible for the oxidative stress section design.

$\mathrm{CP}, \mathrm{MGDC}, \mathrm{FG}, \mathrm{CB}, \mathrm{MF}$ were responsible for the neuroinflammation section design.

$\mathrm{CP}, \mathrm{MGDC}, \mathrm{FG}, \mathrm{CB}, \mathrm{FMC}$ ad MF were responsible for manuscript preparation and writing. All authors critically revised the content of the paper and approved the final version of the manuscript. 


\section{Figure 1 Caption}

Schematic representation of the correlations between olive polyphenols and resveratrol consumption in the MedDiet and neurodegenerative and neuromuscular disorders 


\section{Reference}

[1] Keys, A. Epidemiological Studies Related To Coronary Heart Disease: Characteristics of Men Aged 40-59 in Seven Countries. Acta Med. Scand. 1966, 180, 4-5. https://doi.org/10.1111/j.0954-6820.1966.tb04737.x.

[2] Keys, A. Coronary Heart Disease in Seven Countries. Nutrition 1970, 13 (249, 253), 250-252.

[3] Shen, J.; Wilmot, K. A.; Ghasemzadeh, N.; Molloy, D. L.; Burkman, G.; Mekonnen, G.; Gongora, M. C.; Quyyumi, A. A.; Sperling, L. S. Mediterranean Dietary Patterns and Cardiovascular Health. Annual Review of Nutrition. 2015, pp 425-449. https://doi.org/10.1146/annurev-nutr-011215-02510425974696.

[4] Martínez-González, M. A.; Salas-Salvadó, J.; Estruch, R.; Corella, D.; Fitó, M.; Ros, E. Benefits of the Mediterranean Diet: Insights From the PREDIMED Study. Prog. Cardiovasc. Dis. 2015, 58 (1), 50-60. https://doi.org/10.1016/j.pcad.2015.04.00325940230.

[5] Gouveri, E.; Diamantopoulos, E. J. The Mediterranean Diet and Metabolic Syndrome. In The Mediterranean Diet: An Evidence-Based Approach; 2015; pp 313-323. https://doi.org/10.1016/B978-0-12-407849-9.00029-4.

[6] WHO Europe. Fostering Healthier and More Sustainable Diets - Learning from the Mediterranean and New Nordic Experience. 2018.

[7] Chianese, R.; Coccurello, R.; Viggiano, A.; Scafuro, M.; Fiore, M.; Coppola, G.; Operto, F. F.; Fasano, S.; Laye, S.; Pierantoni, R.; et al. Impact of Dietary Fats on Brain Functions. Curr. Neuropharmacol. 2017, 16 (7), 1059-1085. https://doi.org/10.2174/1570159x1566617101710254729046155.

[8] De Pergola, G.; D'alessandro, A. Influence of Mediterranean Diet on Blood Pressure. Nutrients. 2018. https://doi.org/10.3390/nu1011170030405063.

[9] Carito, V.; Ceccanti, M.; Tarani, L.; Ferraguti, G.; N. Chaldakov, G.; Fiore, M. Neurotrophins' Modulation by Olive Polyphenols. Curr. Med. Chem. 2016, 23 (28), 3189-3197. https://doi.org/10.2174/092986732366616062710402227356540.

[10] Estruch, R.; Martínez-González, M. A.; Corella, D.; Salas-Salvadó, J.; Ruiz-Gutiérrez, V.; Covas, M. I.; Fiol, M.; Gómez-Gracia, E.; López-Sabater, M. C.; Vinyoles, E.; et al. Effects of a Mediterranean-Style Diet on Cardiovascular Risk Factors a Randomized Trial. Ann. Intern. Med. 2006, 145 (1), 1-11. https://doi.org/10.7326/0003-4819-145-1-200607040-0000416818923.

[11] Salas-Salvadó, J.; Bulló, M.; Estruch, R.; Ros, E.; Covas, M. I.; Ibarrola-Jurado, N.; Corella, D.; Arós, F.; Gómez-Gracia, E.; Ruiz-Gutiérrez, V.; et al. Prevention of Diabetes with Mediterranean Diets: A Subgroup Analysis of a Randomized Trial. Ann. Intern. Med. 2014, 160 (1), 1-10. https://doi.org/10.7326/M13172524573661 .

[12] Myburgh, K. H. Polyphenol Supplementation: Benefits for Exercise Performance or Oxidative Stress? Sport. Med. 2014, 44 (SUPPL.1), S57-70. https://doi.org/10.1007/s40279-014-0151-424791917.

[13] Kim, Y. A.; Keogh, J. B.; Clifton, P. M. Polyphenols and Glycémie Control. Nutrients 2016, 8 (1). https://doi.org/10.3390/nu801001726742071.

[14] Tsao, R. Chemistry and Biochemistry of Dietary Polyphenols. Nutrients. 2010, pp 1231-1246. https://doi.org/10.3390/nu212123122254006.

[15] Pandey, K. B.; Rizvi, S. I. Plant Polyphenols as Dietary Antioxidants in Human Health and Disease. Oxidative Medicine and Cellular Longevity. November 2009, pp 270-278. https://doi.org/10.4161/oxim.2.5.949820716914.

[16] Manach, C.; Scalbert, A.; Morand, C.; Rémésy, C.; Jiménez, L. Polyphenols: Food Sources and Bioavailability. Am. J. Clin. Nutr. 2004, 79 (5), 727-747. https://doi.org/10.1093/ajcn/79.5.72715113710.

[17] Constabel, C. P.; Barbehenn, R. Defensive Roles of Polyphenol Oxidase in Plants. In Induced Plant Resistance to Herbivory; Springer, 2008; pp 253-270. https://doi.org/10.1007/978-1-4020-8182-8_12.

[18] Perez-Jimenez, J.; Neveu, V.; Vos, F.; Scalbert, A. Identification of the 100 Richest Dietary Sources of Polyphenols: An Application of the Phenol-Explorer Database. Eur J Clin Nutr 2010, 64 Suppl 3, S112-20.

[19] Guasch-Ferré, M.; Merino, J.; Sun, Q.; Fitó, M.; Salas-Salvadó, J. Dietary Polyphenols, Mediterranean Diet, Prediabetes, and Type 2 Diabetes: A Narrative Review of the Evidence. Oxidative Medicine and Cellular Longevity. 2017. https://doi.org/10.1155/2017/672393128883903.

[20] Bendini, A.; Cerretani, L.; Carrasco-Pancorbo, A.; Gómez-Caravaca, A. M.; Segura-Carretero, A.; FernándezGutiérrez, A.; Lercker, G. Phenolic Molecules in Virgin Olive Oils: A Survey of Their Sensory Properties, Health Effects, Antioxidant Activity and Analytical Methods. An Overview of the Last Decade. Molecules. August 2007, pp 1679-1719. https://doi.org/10.3390/1208167917960082.

[21] Fiore, M.; Messina, M. P.; Petrella, C.; D’Angelo, A.; Greco, A.; Ralli, M.; Ferraguti, G.; Tarani, L.; Vitali, M.; Ceccanti, M. Antioxidant Properties of Plant Polyphenols in the Counteraction of Alcohol-Abuse Induced Damage: Impact on the Mediterranean Diet. J. Funct. Foods 2020, 71, 104012. https://doi.org/10.1016/j.jff.2020.104012.

[22] Ozyilkan, O.; Colak, D.; Akcali, Z.; Basturk, B. Olive: Fruit of Peace against Cancer. Asian Pacific J. Cancer Prev. 2005, 6 (1), 77-8215780038.

[23] Carnevale, R.; Loffredo, L.; Del Ben, M.; Angelico, F.; Nocella, C.; Petruccioli, A.; Bartimoccia, S.; Monticolo, 
R.; Cava, E.; Violi, F. Extra Virgin Olive Oil Improves Post-Prandial Glycemic and Lipid Profile in Patients with Impaired Fasting Glucose. Clin. Nutr. 2017, 36 (3), 782-787. https://doi.org/10.1016/j.clnu.2016.05.01627289163.

[24] Lockyer, S.; Yaqoob, P.; Spencer, J. P. E.; Rowland, I. Olive Leaf Phenolics and Cardiovascular Risk Reduction: Physiological Effects and Mechanisms of Action. Nutr. Aging 2012, 1 (2), 125-140. https://doi.org/10.3233/NUA-2012-0011.

[25] European Parliament; Council of the European Union. Regulation (EU) No 1308/2013 of 17 December 2013. Off. Journasl Eur. Union 2013, 2008 (1308), 184.

[26] Nocella, C.; Cammisotto, V.; Fianchini, L.; D’Amico, A.; Novo, M.; Castellani, V.; Stefanini, L.; Violi, F.; Carnevale, R. Extra Virgin Olive Oil and Cardiovascular Diseases: Benefits for Human Health. Endocrine, Metab. Immune Disord. - Drug Targets 2017, 18 (1), 4-13. https://doi.org/10.2174/187153031766617111412153329141571.

[27] Ros, E. Olive Oil and CVD: Accruing Evidence of a Protective Effect. British Journal of Nutrition. 2012, pp 1931-1933. https://doi.org/10.1017/S000711451200384422950835.

[28] Shrikanta, A.; Kumar, A.; Govindaswamy, V. Resveratrol Content and Antioxidant Properties of Underutilized Fruits. J. Food Sci. Technol. 2015, 52 (1), 383-390. https://doi.org/10.1007/s13197-013-0993-z.

[29] Gambini, J.; Inglés, M.; Olaso, G.; Lopez-Grueso, R.; Bonet-Costa, V.; Gimeno-Mallench, L.; Mas-Bargues, C.; Abdelaziz, K. M.; Gomez-Cabrera, M. C.; Vina, J.; et al. Properties of Resveratrol: In Vitro and In Vivo Studies about Metabolism, Bioavailability, and Biological Effects in Animal Models and Humans. Oxidative Medicine and Cellular Longevity. 2015. https://doi.org/10.1155/2015/83704226221416.

[30] D'Archivio, M.; Filesi, C.; Varì, R.; Scazzocchio, B.; Masella, R. Bioavailability of the Polyphenols: Status and Controversies. Int. J. Mol. Sci. 2010, 11 (4), 1321-1342. https://doi.org/10.3390/ijms1104132120480022.

[31] Yahfoufi, N.; Alsadi, N.; Jambi, M.; Matar, C. The Immunomodulatory and Anti-Inflammatory Role of Polyphenols. Nutrients. 2018. https://doi.org/10.3390/nu1011161830400131.

[32] Xiao, J. B.; Hogger, P. Dietary Polyphenols and Type 2 Diabetes: Current Insights and Future Perspectives. Curr. Med. Chem. 2014, 22 (1), 23-38. https://doi.org/10.2174/092986732166614070613080725005188.

[33] Scalbert, A.; Manach, C.; Morand, C.; Rémésy, C.; Jiménez, L. Dietary Polyphenols and the Prevention of Diseases. Critical Reviews in Food Science and Nutrition. 2005, pp 287-306. https://doi.org/10.1080/104086905909616047496.

[34] M.C. Recio; I. Andujar; J.L. Rios. Anti-Inflammatory Agents from Plants: Progress and Potential. Curr. Med. Chem. 2012, 19 (14), 2088-2103. https://doi.org/10.2174/092986712800229069.

[35] Jemai, H.; Feki, A. E. L.; Sayadi, S. Antidiabetic and Antioxidant Effects of Hydroxytyrosol and Oleuropein from Olive Leaves in Alloxan-Diabetic Rats. J. Agric. Food Chem. 2009, 57 (19), 8798-8804. https://doi.org/10.1021/jf901280r19725535.

[36] Marković, A. K.; Torić, J.; Barbarić, M.; Brala, C. J. Hydroxytyrosol, Tyrosol and Derivatives and Their Potential Effects on Human Health. Molecules. 2019. https://doi.org/10.3390/molecules2410200131137753.

[37] Chaldakov, G. N.; Fiore, M.; Tonchev, A.; Dimitrov, D.; Pancheva, R.; Rancic, G.; Aloe, L. Homo Obesus: A Metabotrophin-Deficient Species. Pharmacology and Nutrition Insight. Curr. Pharm. Des. 2007, 13 (21), 21762179. https://doi.org/10.2174/13816120778103961617627549.

[38] Chaldakov, G. N.; Aloe, L.; Tonchev, A. B.; Fiore, M. From Homo Obesus to Homo Diabesus: Neuroadipology Insight. In Molecular Mechanisms Underpinning the Development of Obesity; 2014; pp 167-178. https://doi.org/10.1007/978-3-319-12766-8_11.

[39] Chaldakov, G. N.; Tonchev, A. B.; Fiore, M.; Kostov, D.; Beltowski, J.; Bojanić, V.; Tunçel, N.; Aloe, L. SOS for Homo Obesus. Obe. Metab. 2010, 6 (1), 1-4.

[40] Leiherer, A.; Mündlein, A.; Drexel, H. Phytochemicals and Their Impact on Adipose Tissue Inflammation and Diabetes. Vascular Pharmacology. 2013, pp 3-20. https://doi.org/10.1016/j.vph.2012.09.00222982056.

[41] Yahfoufi, N.; Mallet, J. F.; Graham, E.; Matar, C. Role of Probiotics and Prebiotics in Immunomodulation. Current Opinion in Food Science. 2018, pp 82-91. https://doi.org/10.1016/j.cofs.2018.04.006.

[42] Li, A. N.; Li, S.; Zhang, Y. J.; Xu, X. R.; Chen, Y. M.; Li, H. Bin. Resources and Biological Activities of Natural Polyphenols. Nutrients. 2014, pp 6020-6047. https://doi.org/10.3390/nu612602025533011.

[43] Watson, R. R.; Preedy, V. R.; Zibadi, S. Polyphenols in Human Health and Disease; 2013; Vol. 1-2. https://doi.org/10.1016/C2011-1-09286-X.

[44] Albarracin, S. L.; Stab, B.; Casas, Z.; Sutachan, J. J.; Samudio, I.; Gonzalez, J.; Gonzalo, L.; Capani, F.; Morales, L.; Barreto, G. E. Effects of Natural Antioxidants in Neurodegenerative Disease. Nutr. Neurosci. 2012, 15 (1), 1-9. https://doi.org/10.1179/1476830511Y.000000002822305647.

[45] Caruso, F.; Tanski, J.; Villegas-Estrada, A.; Rossi, M. Structural Basis for Antioxidant Activity of TransResveratrol: Ab Initio Calculations and Crystal and Molecular Structure. J. Agric. Food Chem. 2004, 52 (24), 7279-7285. https://doi.org/10.1021/jf048794e15563207.

[46] Gülçin, I. Antioxidant Properties of Resveratrol: A Structure-Activity Insight. Innov. Food Sci. Emerg. Technol. 2010, 11 (1), 210-218. https://doi.org/10.1016/j.ifset.2009.07.002.

[47] Öztürk, E.; Arslan, A. K. K.; Yerer, M. B.; Bishayee, A. Resveratrol and Diabetes: A Critical Review of Clinical Studies. Biomedicine and Pharmacotherapy. 2017, pp 230-234. 
https://doi.org/10.1016/j.biopha.2017.08.07028843911.

[48] Rauf, A.; Imran, M.; Sulera, H. A. R.; Ahmad, B.; Peters, D. G.; Mubarak, M. S. A Comprehensive Review of the Health Perspectives of Resveratrol. Food and Function. 2017, pp 4284-4305. https://doi.org/10.1039/c7fo01300k29044265.

[49] Jardim, F. R.; de Rossi, F. T.; Nascimento, M. X.; da Silva Barros, R. G.; Borges, P. A.; Prescilio, I. C.; de Oliveira, M. R. Resveratrol and Brain Mitochondria: A Review. Molecular Neurobiology. 2018, pp 2085-2101. https://doi.org/10.1007/s12035-017-0448-z28283884.

[50] Li, Y. R.; Li, S.; Lin, C. C. Effect of Resveratrol and Pterostilbene on Aging and Longevity. BioFactors. 2018, pp 69-82. https://doi.org/10.1002/biof.140029210129.

[51] Salehi, B.; Mishra, A. P.; Nigam, M.; Sener, B.; Kilic, M.; Sharifi-Rad, M.; Fokou, P. V. T.; Martins, N.; Sharifi-Rad, J. Resveratrol: A Double-Edged Sword in Health Benefits. Biomedicines. 2018. https://doi.org/10.3390/biomedicines6030091.

[52] Liu, Y.; He, X. Q.; Huang, X.; Ding, L.; Xu, L.; Shen, Y. T.; Zhang, F.; Zhu, M. B.; Xu, B. H.; Qi, Z. Q.; et al. Resveratrol Protects Mouse Oocytes from Methylglyoxal-Induced Oxidative Damage. PLoS One 2013, 8 (10). https://doi.org/10.1371/journal.pone.007796024194906.

[53] Liguori, I.; Russo, G.; Curcio, F.; Bulli, G.; Aran, L.; Della-Morte, D.; Gargiulo, G.; Testa, G.; Cacciatore, F.; Bonaduce, D.; et al. Oxidative Stress, Aging, and Diseases. Clinical Interventions in Aging. 2018, pp 757-772. https://doi.org/10.2147/CIA.S15851329731617.

[54] Plauth, A.; Geikowski, A.; Cichon, S.; Wowro, S. J.; Liedgens, L.; Rousseau, M.; Weidner, C.; Fuhr, L.; Kliem, M.; Jenkins, G.; et al. Hormetic Shifting of Redox Environment by Pro-Oxidative Resveratrol Protects Cells against Stress. Free Radic. Biol. Med. 2016, 99, 608-622. https://doi.org/10.1016/j.freeradbiomed.2016.08.00627515816.

[55] Sgarbi, G.; Liuzzi, F.; Baracca, A.; Solaini, G. Resveratrol Preserves Mitochondrial Function in a Human PostMitotic Cell Model. J. Nutr. Biochem. 2018, 62, 9-17. https://doi.org/10.1016/j.jnutbio.2018.07.01730216747.

[56] Cheng, K.; Song, Z.; Zhang, H.; Li, S.; Wang, C.; Zhang, L.; Wang, T. The Therapeutic Effects of Resveratrol on Hepatic Steatosis in High-Fat Diet-Induced Obese Mice by Improving Oxidative Stress, Inflammation and Lipid-Related Gene Transcriptional Expression. Med. Mol. Morphol. 2019, 52 (4), 187-197. https://doi.org/10.1007/s00795-019-00216-730673851.

[57] Hussein, M. M. A.; Mahfouz, M. K. Effect of Resveratrol and Rosuvastatin on Experimental Diabetic Nephropathy in Rats. Biomed. Pharmacother. 2016, 82, 685-692. https://doi.org/10.1016/j.biopha.2016.06.00427470412.

[58] Brasnyó, P.; Molnár, G. A.; Mohás, M.; Markó, L.; Laczy, B.; Cseh, J.; Mikolás, E.; Szijártó, I. A.; Mérei, Á.; Halmai, R.; et al. Resveratrol Improves Insulin Sensitivity, Reduces Oxidative Stress and Activates the Akt Pathway in Type 2 Diabetic Patients. Br. J. Nutr. 2011, 106 (3), 383-389. https://doi.org/10.1017/S000711451100031621385509.

[59] Imamura, H.; Yamaguchi, T.; Nagayama, D.; Saiki, A.; Shirai, K.; Tatsuno, I. Resveratrol Ameliorates Arterial Stiffness Assessed by Cardio-Ankle Vascular Index in Patients with Type 2 Diabetes Mellitus. Int. Heart J. 2017, 58 (4), 577-583. https://doi.org/10.1536/ihj.16-37328701674.

[60] Simental-Mendía, L. E.; Guerrero-Romero, F. Effect of Resveratrol Supplementation on Lipid Profile in Subjects with Dyslipidemia: A Randomized Double-Blind, Placebo-Controlled Trial. Nutrition 2019, 58, 7-10. https://doi.org/10.1016/j.nut.2018.06.01530278430.

[61] Timmers, S.; De Ligt, M.; Phielix, E.; Van De Weijer, T.; Hansen, J.; Moonen-Kornips, E.; Schaart, G.; Kunz, I.; Hesselink, M. K. C.; Schrauwen-Hinderling, V. B.; et al. Resveratrol as Add-on Therapy in Subjects with Well-Controlled Type 2 Diabetes: A Randomized Controlled Trial. Diabetes Care 2016, 39 (12), 2211-2217. https://doi.org/10.2337/dc16-049927852684.

[62] A. Qureshi, A.; A. Khan, D.; Mahjabeen, W. Suppression of Nitric Oxide Production and Cardiovascular Risk Factors in Healthy Seniors and Hypercholesterolemic Subjects by a Combination of Polyphenols and Vitamins. J. Clin. Exp. Cardiolog. 2012, 01 (S5). https://doi.org/10.4172/2155-9880.s5-008.

[63] Aloe, L.; Fiore, M. TNF- $\alpha$ Expressed in the Brain of Transgenic Mice Lowers Central Tyroxine Hydroxylase Immunoreactivity and Alters Grooming Behavior. Neurosci. Lett. 1997, 238 (1-2), 65-68. https://doi.org/10.1016/S0304-3940(97)00850-19464656.

[64] Lugrin, J.; Rosenblatt-Velin, N.; Parapanov, R.; Liaudet, L. The Role of Oxidative Stress during Inflammatory Processes. Biological Chemistry. 2014, pp 203-230. https://doi.org/10.1515/hsz-2013-024124127541.

[65] Grivennikov, S. I.; Greten, F. R.; Karin, M. Immunity, Inflammation, and Cancer. Cell. 2010, pp 883-899. https://doi.org/10.1016/j.cell.2010.01.02520303878.

[66] Tarani, L.; Carito, V.; Ferraguti, G.; Petrella, C.; Greco, A.; Ralli, M.; Messina, M. P.; Rasio, D.; De Luca, E.; Putotto, C.; et al. Neuroinflammatory Markers in the Serum of Prepubertal Children with down Syndrome. $J$. Immunol. Res. 2020, 2020, 6937154. https://doi.org/10.1155/2020/693715432280719.

[67] Aloe, L.; Fiore, M.; Probert, L.; Turrini, P.; Tirassa, P. Overexpression of Tumour Necrosis Factor Alpha in the Brain of Transgenic Mice Differentially Alters Nerve Growth Factor Levels and Choline Acetyltransferase Activity. Cytokine 1999, 11 (1), 45-54. https://doi.org/10.1006/cyto.1998.039710080878.

[68] Fiore, M.; Alleva, E.; Probert, L.; Kollias, G.; Angelucci, F.; Aloe, L. Exploratory and Displacement Behavior 
in Transgenic Mice Expressing High Levels of Brain TNF-. Physiol. Behav. 1998, 63 (4), 571-576. https://doi.org/10.1016/S0031-9384(97)00514-39523900.

[69] Turner, M. D.; Nedjai, B.; Hurst, T.; Pennington, D. J. Cytokines and Chemokines: At the Crossroads of Cell Signalling and Inflammatory Disease. Biochimica et Biophysica Acta - Molecular Cell Research. 2014, pp 2563-2582. https://doi.org/10.1016/j.bbamcr.2014.05.01424892271.

[70] Mittal, M.; Siddiqui, M. R.; Tran, K.; Reddy, S. P.; Malik, A. B. Reactive Oxygen Species in Inflammation and Tissue Injury. Antioxidants and Redox Signaling. 2014, pp 1126-1167. https://doi.org/10.1089/ars.2012.514923991888.

[71] Fukata, M.; Arditi, M. The Role of Pattern Recognition Receptors in Intestinal Inflammation. Mucosal Immunology. 2013, pp 451-463. https://doi.org/10.1038/mi.2013.1323515136.

[72] Wang, G.; Hu, Z.; Fu, Q.; Song, X.; Cui, Q.; Jia, R.; Zou, Y.; He, C.; Li, L.; Yin, Z. Resveratrol Mitigates

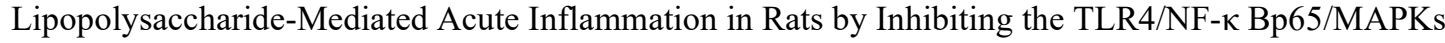
Signaling Cascade. Sci. Rep. 2017, 7. https://doi.org/10.1038/srep4500628322346.

[73] Youn, H. S.; Lee, J. Y.; Fitzgerald, K. A.; Young, H. A.; Akira, S.; Hwang, D. H. Specific Inhibition of MyD88-Independent Signaling Pathways of TLR3 and TLR4 by Resveratrol: Molecular Targets Are TBK1 and RIP1 in TRIF Complex. J. Immunol. 2005, 175 (5), 3339-3346. https://doi.org/10.4049/jimmunol.175.5.333916116226.

[74] Dong, J.; Sulik, K. K.; Chen, S. Y. Nrf2-Mediated Transcriptional Induction of Antioxidant Response in Mouse Embryos Exposed to Ethanol in Vivo: Implications for the Prevention of Fetal Alcohol Spectrum Disorders. Antioxidants Redox Signal. 2008, 10 (12), 2023-2033. https://doi.org/10.1089/ars.2007.201918759561.

[75] Farkhondeh, T.; Folgado, S. L.; Pourbagher-Shahri, A. M.; Ashrafizadeh, M.; Samarghandian, S. The Therapeutic Effect of Resveratrol: Focusing on the Nrf2 Signaling Pathway. Biomed. Pharmacother. 2020, 127, 110234. https://doi.org/10.1016/j.biopha.2020.11023432559855.

[76] Qu, Y.; Wang, C.; Liu, N.; Gao, C.; Liu, F. Morin Exhibits Anti-Inflammatory Effects on IL-1 $\beta$-Stimulated Human Osteoarthritis Chondrocytes by Activating the Nrf2 Signaling Pathway. Cell. Physiol. Biochem. 2018, 51 (4), 1830-1838. https://doi.org/10.1159/00049568430504721.

[77] Chen, W. P.; Wang, Y. L.; Tang, J. L.; Hu, P. F.; Bao, J. P.; Wu, L. D. Morin Inhibits Interleukin-1 $\beta$-Induced Nitric Oxide and Prostaglandin E 2 Production in Human Chondrocytes. Int. Immunopharmacol. 2012, 12 (2), 447-452. https://doi.org/10.1016/j.intimp.2011.12.02422244821.

[78] Wei, Y.; Jia, J.; Jin, X.; Tong, W.; Tian, H. Resveratrol Ameliorates Inflammatory Damage and Protects against Osteoarthritis in a Rat Model of Osteoarthritis. Mol. Med. Rep. 2018, 17 (1), 1493-1498. https://doi.org/10.3892/mmr.2017.803629138829.

[79] Park, S.; Lee, L. R.; Seo, J. H.; Kang, S. Curcumin and Tetrahydrocurcumin Both Prevent Osteoarthritis Symptoms and Decrease the Expressions of Pro-Inflammatory Cytokines in Estrogen-Deficient Rats. Genes Nutr. 2016, 11 (1). https://doi.org/10.1186/s12263-016-0520-4.

[80] Carito, V.; Ciafrè, S.; Tarani, L.; Ceccanti, M.; Natella, F.; Iannitelli, A.; Tirassa, P.; Chaldakov, G. N.; Ceccanti, M.; Boccardo, C.; et al. TNF- $\alpha$ and IL-10 Modulation Induced by Polyphenols Extracted by Olive Pomace in a Mouse Model of Paw Inflammation. Ann. Ist. Super. Sanita 2015, 51 (4), 382-386. https://doi.org/10.4415/ANN-15-04-2126783228.

[81] Yang, J.; Li, S.; Xie, C.; Ye, H.; Tang, H.; Chen, L.; Peng, A. Anti-Inflammatory Activity of Ethyl Acetate Fraction of the Seeds of Brucea Javanica. J. Ethnopharmacol. 2013, 147 (2), 442-446. https://doi.org/10.1016/j.jep.2013.03.03423538165.

[82] Hosseinpour-Niazi, S.; Mirmiran, P.; Fallah-Ghohroudi, A.; Azizi, F. Non-Soya Legume-Based Therapeutic Lifestyle Change Diet Reduces Inflammatory Status in Diabetic Patients: A Randomised Cross-over Clinical Trial. Br. J. Nutr. 2015, 114 (2), 213-219. https://doi.org/10.1017/S000711451500172526077375.

[83] Ceccanti, M.; Coccurello, R.; Carito, V.; Ciafrè, S.; Ferraguti, G.; Giacovazzo, G.; Mancinelli, R.; Tirassa, P.; Chaldakov, G. N.; Pascale, E.; et al. Paternal Alcohol Exposure in Mice Alters Brain NGF and BDNF and Increases Ethanol-Elicited Preference in Male Offspring. Addict. Biol. 2016, 21 (4), 776-787. https://doi.org/10.1111/adb.1225525940002.

[84] Ceccanti, M.; Coriale, G.; Hamilton, D. A.; Carito, V.; Coccurello, R.; Scalese, B.; Ciafrè, S.; Codazzo, C.; Messina, M. P.; Chaldakov, G. N.; et al. Virtual Morris Task Responses in Individuals in an Abstinence Phase from Alcohol. Can. J. Physiol. Pharmacol. 2018, 96 (2), 128-136. https://doi.org/10.1139/cjpp-2017001328763626 .

[85] Ceccanti, M.; Hamilton, D.; Coriale, G.; Carito, V.; Aloe, L.; Chaldakov, G.; Romeo, M.; Ceccanti, M.; Iannitelli, A.; Fiore, M. Spatial Learning in Men Undergoing Alcohol Detoxification. Physiol. Behav. 2015, 149, 324-330. https://doi.org/10.1016/j.physbeh.2015.06.03426143187.

[86] Carito, V.; Parlapiano, G.; Rasio, D.; Paparella, R.; Paolucci, V.; Ferraguti, G.; Greco, A.; Ralli, M.; Pichini, S.; Fiore, M.; et al. Fetal Alcohol Spectrum Disorders in Pediatrics. FASD and the Pediatrician. Biomed. Rev. 2018, 29 (0), 27. https://doi.org/10.14748/bmr.v29.5847.

[87] Ridley, N. J.; Draper, B.; Withall, A. Alcohol-Related Dementia: An Update of the Evidence. Alzheimer's Res. Ther. 2013, 5 (1). https://doi.org/10.1186/alzrt157.

[88] Schwarzinger, M.; Pollock, B. G.; Hasan, O. S. M.; Dufouil, C.; Rehm, J.; Baillot, S.; Guibert, Q.; Planchet, F.; 
Luchini, S. Contribution of Alcohol Use Disorders to the Burden of Dementia in France 2008-13: A Nationwide Retrospective Cohort Study. Lancet Public Heal. 2018, 3 (3), e124-e132. https://doi.org/10.1016/S2468-2667(18)30022-729475810.

[89] Roerecke, M.; Rehm, J. Cause-Specific Mortality Risk in Alcohol Use Disorder Treatment Patients: A Systematic Review and Meta-Analysis. Int. J. Epidemiol. 2014. https://doi.org/10.1093/ije/dyu018.

[90] Ceccanti, M.; De Nicolò, S.; Mancinelli, R.; Chaldakov, G.; Carito, V.; Ceccanti, M.; Laviola, G.; Tirassa, P.; Fiore, M. NGF and BDNF Long-Term Variations in the Thyroid, Testis and Adrenal Glands of a Mouse Model of Fetal Alcohol Spectrum Disorders. Ann. Ist. Super. Sanita 2013, 49 (4), 383-390. https://doi.org/10.4415/ANN-13-04-1124334784.

[91] Ceccanti, M.; Inghilleri, M.; Attilia, M. L.; Raccah, R.; Fiore, M.; Zangen, A.; Ceccanti, M. Deep TMS on Alcoholics: Effects on Cortisolemia and Dopamine Pathway Modulation. A Pilot Study. Can. J. Physiol. Pharmacol. 2015, 93 (4), 283-290. https://doi.org/10.1139/cjpp-2014-018825730614.

[92] Ferraguti, G.; Pascale, E.; Lucarelli, M. Alcohol Addiction: A Molecular Biology Perspective. Curr. Med. Chem. 2015, 22 (6), 670-684. https://doi.org/10.2174/092986732166614122910315825544474.

[93] Ceccanti, M.; Mancinelli, R.; Tirassa, P.; Laviola, G.; Rossi, S.; Romeo, M.; Fiore, M. Early Exposure to Ethanol or Red Wine and Long-Lasting Effects in Aged Mice. A Study on Nerve Growth Factor, Brain-Derived Neurotrophic Factor, Hepatocyte Growth Factor, and Vascular Endothelial Growth Factor. Neurobiol. Aging 2012, 33 (2), 359-367. https://doi.org/10.1016/j.neurobiolaging.2010.03.00520382450.

[94] Fiore, M.; Chaldakov, G. N.; Aloe, L. Nerve Growth Factor as a Signaling Molecule for Nerve Cells and Also for the Neuroendocrine-Immune Systems. Rev. Neurosci. 2009, 20 (2), 133-145. https://doi.org/10.1515/REVNEURO.2009.20.2.13319774790.

[95] Pereira, P. A.; Rocha, J. P.; Cardoso, A.; Vilela, M.; Sousa, S.; Madeira, M. D. Effects of Chronic Alcohol Consumption, Withdrawal and Nerve Growth Factor on Neuropeptide Y Expression and Cholinergic Innervation of the Rat Dentate Hilus. Neurotoxicology 2016. https://doi.org/10.1016/j.neuro.2016.04.007.

[96] Carito, V.; Ceccanti, M.; Ferraguti, G.; Coccurello, R.; Ciafrè, S.; Tirassa, P.; Fiore, M. NGF and BDNF Alterations by Prenatal Alcohol Exposure. Curr. Neuropharmacol. 2017, 17 (4), 308-317. https://doi.org/10.2174/1570159x15666170825101308.

[97] Chaldakov, G. N.; Fiore, M.; Ghenev, P. I.; Stankulov, I. S.; Aloe, L. Atherosclerotic Lesions: Possible Interactive Involvement of Intima, Adventitia and Associated Adipose Tissue. Int. Med. J. 2000, 7 (1), $43-49$.

[98] Ceci, F. M.; Ferraguti, G.; Petrella, C.; Greco, A.; Ralli, M.; Iannitelli, A.; Carito, V.; Tirassa, P.; Chaldakov, G. N.; Messina, M. P.; et al. Nerve Growth Factor in Alcohol Use Disorders. Curr. Neuropharmacol. 2020, 18. https://doi.org/10.2174/1570159x1866620042900323932348226.

[99] Fiore, M.; Laviola, G.; Aloe, L.; di Fausto, V.; Mancinelli, R.; Ceccanti, M. Early Exposure to Ethanol but Not Red Wine at the Same Alcohol Concentration Induces Behavioral and Brain Neurotrophin Alterations in Young and Adult Mice. Neurotoxicology 2009, 30 (1), 59-71. https://doi.org/10.1016/j.neuro.2008.11.00919100286.

[100] Manni, L.; Aloe, L.; Fiore, M. Changes in Cognition Induced by Social Isolation in the Mouse Are Restored by Electro-Acupuncture. Physiol. Behav. 2009, 98 (5), 537-542. https://doi.org/10.1016/j.physbeh.2009.08.01119733189.

[101] Angelucci, F.; Piermaria, J.; Gelfo, F.; Shofany, J.; Tramontano, M.; Fiore, M.; Caltagirone, C.; Peppe, A. The Effects of Motor Rehabilitation Training on Clinical Symptoms and Serum BDNF Levels in Parkinson's Disease Subjects. Can. J. Physiol. Pharmacol. 2016, 94 (4), 455-461. https://doi.org/10.1139/cjpp-2015032226863448 .

[102] Ciafre, S.; Ferraguti, G.; Tirassa, P.; Iannitelli, A.; Ralli, M.; Greco, A.; Chaldakov, G. N.; Rosso, P.; Fico, E.; Messina, M. P.; et al. Nerve Growth Factor in the Psychiatric Brain. Riv. Psichiatr. 2020, 55 (1), 4-15. https://doi.org/10.1708/3301.3271332051620.

[103] Sasi, M.; Vignoli, B.; Canossa, M.; Blum, R. Neurobiology of Local and Intercellular BDNF Signaling. Pflugers Archiv : European journal of physiology. 2017, pp 593-610. https://doi.org/10.1007/s00424-017-1964428280960.

[104] Elamin, E. E.; Masclee, A. A.; Dekker, J.; Jonkers, D. M. Ethanol Metabolism and Its Effects on the Intestinal Epithelial Barrier. Nutr. Rev. 2013, 71 (7), 483-499. https://doi.org/10.1111/nure.1202723815146.

[105] Ciafrè, S.; Carito, V.; Ferraguti, G.; Greco, A.; Chaldakov, G. N.; Fiore, M.; Ceccanti, M. How Alcohol Drinking Affects Our Genes: An Epigenetic Point of View. Biochem. Cell Biol. 2018, 1-12. https://doi.org/10.1139/bcb-2018-024830412425.

[106] Lieber, C. S.; Rubin, E.; DeCarli, L. M. Hepatic Microsomal Ethanol Oxidizing System (MEOS): Differentiation from Alcohol Dehydrogenase and NADPH Oxidase. Biochem. Biophys. Res. Commun. 1970, 40 (4), 858-865. https://doi.org/10.1016/0006-291X(70)90982-44395603.

[107] O’Shea, R. S.; Dasarathy, S.; McCullough, A. J.; Shuhart, M. C.; Davis, G. L.; Franco, J.; Harrison, S. A.; Howell, C. D.; Ling, S. C.; Liu, L. U.; et al. Alcoholic Liver Disease. Hepatology. 2010, pp 307-328. https://doi.org/10.1002/hep.2325820034030.

[108] Talib, W. H.; Alsayed, A. R.; Farhan, F.; Al Kury, L. T. Resveratrol and Tumor Microenvironment: Mechanistic Basis and Therapeutic Targets. Molecules 2020, 25 (18), 4282.

[109] Siracusa, R.; Scuto, M.; Fusco, R.; Trovato, A.; Ontario, M. L.; Crea, R.; Di Paola, R.; Cuzzocrea, S.; 
Calabrese, V. Anti-Inflammatory and Anti-Oxidant Activity of Hidrox ${ }^{\circledR}$ in Rotenone-Induced Parkinson's Disease in Mice. Antioxidants 2020, 9 (9), 1-19. https://doi.org/10.3390/antiox9090824.

[110] De Nicoló, S.; Tarani, L.; Ceccanti, M.; Maldini, M.; Natella, F.; Vania, A.; Chaldakov, G. N.; Fiore, M. Effects of Olive Polyphenols Administration on Nerve Growth Factor and Brain-Derived Neurotrophic Factor in the Mouse Brain. Nutrition 2013, 29 (4), 681-687. https://doi.org/10.1016/j.nut.2012.11.00723466052.

[111] Carito, V.; Ceccanti, M.; Chaldakov, G.; Tarani, L.; De Nicolò, S.; Ciafrè, S.; Tirassa, P.; Fiore, M. Polyphenols, Nerve Growth Factor, Brain-Derived Neurotrophic Factor, and the Brain. Bioact. Nutraceuticals Diet. Suppl. Neurol. Brain Dis. Prev. Ther. 2015, 65-71. https://doi.org/10.1016/B978-0-12-411462-3.00007-2.

[112] Carito, V.; Venditti, A.; Bianco, A.; Ceccanti, M.; Serrilli, A. M.; Chaldakov, G.; Tarani, L.; De Nicolò, S.; Fiore, M. Effects of Olive Leaf Polyphenols on Male Mouse Brain NGF, BDNF and Their Receptors TrkA, TrkB and P75. Nat. Prod. Res. 2014, 28 (22), 1970-1984. https://doi.org/10.1080/14786419.2014.91897724865115.

[113] Carito, V.; Ceccanti, M.; Cestari, V.; Natella, F.; Bello, C.; Coccurello, R.; Mancinelli, R.; Fiore, M. Olive Polyphenol Effects in a Mouse Model of Chronic Ethanol Addiction. Nutrition 2017, 33, 65-69. https://doi.org/10.1016/j.nut.2016.08.01427908553.

[114] Valentina Carito, M. C. Serum BDNF and NGF Modulation by Olive Polyphenols in Alcoholics during Withdrawal. J. Alcohol. Drug Depend. 2015, 03 (04). https://doi.org/10.4172/2329-6488.1000214.

[115] Petrella, C.; Carito, V.; Carere, C.; Ferraguti, G.; Ciafrè, S.; Natella, F.; Bello, C.; Greco, A.; Ralli, M.; Mancinelli, R.; et al. Oxidative Stress Inhibition by Resveratrol in Alcohol-Dependent Mice. Nutrition 2020, 79-80. https://doi.org/10.1016/j.nut.2020.110783.

[116] Ciafrè, S.; Ferraguti, G.; Greco, A.; Polimeni, A.; Ralli, M.; Ceci, F. M.; Ceccanti, M.; Fiore, M. Alcohol as an Early Life Stressor: Epigenetics, Metabolic, Neuroendocrine and Neurobehavioral Implications. Neurosci. Biobehav. Rev. 2020, 118, 654-668. https://doi.org/10.1016/j.neubiorev.2020.08.01832976915.

[117] Coriale, G.; Fiorentino, D.; Lauro, F. D. I.; Marchitelli, R.; Scalese, B.; Fiore, M.; Maviglia, M.; Ceccanti, M. Fetal Alcohol Spectrum Disorder (FASD): Neurobehavioral Profile, Indications for Diagnosis and Treatment. Riv. Psichiatr. 2013, 48 (5), 359-369. https://doi.org/10.1708/1356.15062.

[118] De Nicolò, S.; Carito, V.; Fiore, M.; Laviola, G. Aberrant Behavioral and Neurobiologic Profiles in Rodents Exposed to Ethanol or Red Wine Early in Development. Curr. Dev. Disord. Reports 2014, 1 (3), 173-180. https://doi.org/10.1007/s40474-014-0023-5.

[119] Fiore, M.; Mancinelli, R.; Aloe, L.; Laviola, G.; Sornelli, F.; Vitali, M.; Ceccanti, M. Hepatocyte Growth Factor, Vascular Endothelial Growth Factor, Glial Cell-Derived Neurotrophic Factor and Nerve Growth Factor Are Differentially Affected by Early Chronic Ethanol or Red Wine Intake. Toxicol. Lett. 2009, 188 (3), 208213. https://doi.org/10.1016/j.toxlet.2009.04.01319397965.

[120] Petrella, C.; Farioli-Vecchioli, S.; Cisale, G. Y.; Strimpakos, G.; Borg, J. J.; Ceccanti, M.; Fiore, M.; Monteleone, G.; Nisticò, R. A Healthy Gut for a Healthy Brain: Preclinical, Clinical and Regulatory Aspects. Curr. Neuropharmacol. 2020. https://doi.org/10.2174/1570159X1866620073011152832744976.

[121] Guiling, M.; Yanting, C. Polyphenol Supplementation Benefits Human Health via Gut Microbiota: A Systematic Review via Meta-Analysis. J. Funct. Foods 2020, 66, 103829. https://doi.org/10.1016/j.jff.2020.103829.

[122] Nash, V.; Ranadheera, C. S.; Georgousopoulou, E. N.; Mellor, D. D.; Panagiotakos, D. B.; McKune, A. J.; Kellett, J.; Naumovski, N. The Effects of Grape and Red Wine Polyphenols on Gut Microbiota - A Systematic Review. Food Res. Int. 2018, 113, 277-287. https://doi.org/10.1016/j.foodres.2018.07.01930195522.

[123] Queipo-Ortuño, M. I.; Boto-Ordóñez, M.; Murri, M.; Gomez-Zumaquero, J. M.; Clemente-Postigo, M.; Estruch, R.; Cardona Diaz, F.; Andrés-Lacueva, C.; Tinahones, F. J. Influence of Red Wine Polyphenols and Ethanol on the Gut Microbiota Ecology and Biochemical Biomarkers. Am. J. Clin. Nutr. 2012, 95 (6), 1323 1334. https://doi.org/10.3945/ajcn.111.02784722552027.

[124] Jacobs, D. M.; Fuhrmann, J. C.; van Dorsten, F. A.; Rein, D.; Peters, S.; van Velzen, E. J. J.; Hollebrands, B.; Draijer, R.; van Duynhoven, J.; Garczarek, U. Impact of Short-Term Intake of Red Wine and Grape Polyphenol Extract on the Human Metabolome. J. Agric. Food Chem. 2012, 60 (12), 3078-3085. https://doi.org/10.1021/jf204424722372405.

[125] Rotches-Ribalta, M.; Urpi-Sarda, M.; Martí, M. M.; Reglero, G.; Andres-Lacueva, C. Resveratrol Metabolic Fingerprinting after Acute and Chronic Intakes of a Functional Beverage in Humans. Electrophoresis 2014, 35 (11), 1637-1643. https://doi.org/10.1002/elps.20130026224254301.

[126] Stalmach, A.; Edwards, C. A.; Wightman, J. D.; Crozier, A. Gastrointestinal Stability and Bioavailability of (Poly)Phenolic Compounds Following Ingestion of Concord Grape Juice by Humans. Mol. Nutr. Food Res. 2012, 56 (3), 497-509. https://doi.org/10.1002/mnfr.20110056622331633.

[127] Corella, D.; Coltell, O.; Macian, F.; Ordovás, J. M. Advances in Understanding the Molecular Basis of the Mediterranean Diet Effect. Annu. Rev. Food Sci. Technol. 2018, 9, 227-249. https://doi.org/10.1146/annurevfood-032217-02080229400994.

[128] Herrera-Marcos, L. V; Lou-Bonafonte, J. M.; Arnal, C.; Navarro, M. A.; Osada, J. Transcriptomics and the Mediterranean Diet: A Systematic Review. Nutrients 2017, 9 (5). https://doi.org/10.3390/nu905047228486416.

[129] Catalanotto, C.; Cogoni, C.; Zardo, G. MicroRNA in Control of Gene Expression: An Overview of Nuclear 
Functions. Int. J. Mol. Sci. 2016, 17 (10). https://doi.org/10.3390/ijms1710171227754357.

[130] He, J.; Tu, C.; Liu, Y. Role of LncRNAs in Aging and Age-Related Diseases. Aging Med. (milt. 2018, 1 (2), 158-175. https://doi.org/10.1002/agm2.1203031942494.

[131] Arora, I.; Sharma, M.; Sun, L. Y.; Tollefsbol, T. O. The Epigenetic Link between Polyphenols, Aging and AgeRelated Diseases. Genes (Basel). 2020, 11 (9). https://doi.org/10.3390/genes1 109109432962067.

[132] Barbato, C.; Ruberti, F. Mapping of Nervous System Diseases via MicroRNAs; 2016. https://doi.org/10.1201/b19229.

[133] Masotti, A.; Baldassarre, A.; Guzzo, M. P.; Iannuccelli, C.; Barbato, C.; Di Franco, M. Circulating MicroRNA Profiles as Liquid Biopsies for the Characterization and Diagnosis of Fibromyalgia Syndrome. Mol. Neurobiol. 2017, 54 (9), 7129-7136. https://doi.org/10.1007/s12035-016-0235-227796750.

[134] Izzotti, A.; Cartiglia, C.; Steele, V. E.; De Flora, S. MicroRNAs as Targets for Dietary and Pharmacological Inhibitors of Mutagenesis and Carcinogenesis. Mutat. Res. 2012, 751 (2), 287-303. https://doi.org/10.1016/j.mrrev.2012.05.00422683846.

[135] García-Segura, L.; Pérez-Andrade, M.; Miranda-Ríos, J. The Emerging Role of MicroRNAs in the Regulation of Gene Expression by Nutrients. J. Nutrigenet. Nutrigenomics 2013, 6 (1), 16-31. https://doi.org/10.1159/00034582623445777.

[136] Williams, R. J.; Spencer, J. P. E. Flavonoids, Cognition, and Dementia: Actions, Mechanisms, and Potential Therapeutic Utility for Alzheimer Disease. Free Radic. Biol. Med. 2012, 52 (1), 35-45. https://doi.org/10.1016/j.freeradbiomed.2011.09.01021982844.

[137] Takousis, P.; Sadlon, A.; Schulz, J.; Wohlers, I.; Dobricic, V.; Middleton, L.; Lill, C. M.; Perneczky, R.; Bertram, L. Differential Expression of MicroRNAs in Alzheimer's Disease Brain, Blood, and Cerebrospinal Fluid. Alzheimers. Dement. 2019, 15 (11), 1468-1477. https://doi.org/10.1016/j.jalz.2019.06.495231495604.

[138] Serna, E.; Gambini, J.; Borras, C.; Abdelaziz, K. M.; Belenguer, A.; Sanchis, P.; Avellana, J. A.; RodriguezMañas, L.; Viña, J. Centenarians, but Not Octogenarians, up-Regulate the Expression of MicroRNAs. Sci. Rep. 2012, 2, 961. https://doi.org/10.1038/srep0096123233880.

[139] Borras, C.; Abdelaziz, K. M.; Gambini, J.; Serna, E.; Inglés, M.; de la Fuente, M.; Garcia, I.; Matheu, A.; Sanchís, P.; Belenguer, A.; et al. Human Exceptional Longevity: Transcriptome from Centenarians Is Distinct from Septuagenarians and Reveals a Role of Bcl-XL in Successful Aging. Aging (Albany. NY). 2016, 8 (12), 3185-3208. https://doi.org/10.18632/aging.10107827794564.

[140] ElSharawy, A.; Keller, A.; Flachsbart, F.; Wendschlag, A.; Jacobs, G.; Kefer, N.; Brefort, T.; Leidinger, P.; Backes, C.; Meese, E.; et al. Genome-Wide MiRNA Signatures of Human Longevity. Aging Cell 2012, 11 (4), 607-616. https://doi.org/10.1111/j.1474-9726.2012.00824.x22533606.

[141] Borrás, C.; Serna, E.; Gambini, J.; Inglés, M.; Vina, J. Centenarians Maintain MiRNA Biogenesis Pathway While It Is Impaired in Octogenarians. Mech. Ageing Dev. 2017, 168, 54-57. https://doi.org/10.1016/j.mad.2017.07.00328754532.

[142] López-Otín, C.; Blasco, M. A.; Partridge, L.; Serrano, M.; Kroemer, G. The Hallmarks of Aging. Cell 2013, 153 (6), 1194-1217. https://doi.org/10.1016/j.cell.2013.05.03923746838.

[143] Isac, S.; Panaitescu, A. M.; Spataru, A.; Iesanu, M.; Totan, A.; Udriste, A.; Cucu, N.; Peltecu, G.; Zagrean, L.; Zagrean, A. M. Trans-Resveratrol Enriched Maternal Diet Protects the Immature Hippocampus from Perinatal Asphyxia in Rats. Neurosci. Lett. 2017, 653, 308-313. https://doi.org/10.1016/j.neulet.2017.06.00328595952.

[144] Matboli, M.; Eissa, S.; Ibrahim, D.; Hegazy, M. G. A.; Imam, S. S.; Habib, E. K. Caffeic Acid Attenuates Diabetic Kidney Disease via Modulation of Autophagy in a High-Fat Diet/Streptozotocin- Induced Diabetic Rat. Sci. Rep. 2017, 7 (1), 2263. https://doi.org/10.1038/s41598-017-02320-z28536471.

[145] Zhao, Q.; Li, S.; Li, N.; Yang, X.; Ma, S.; Yang, A.; Zhang, H.; Yang, S.; Mao, C.; Xu, L.; et al. MiR-34a Targets HDAC1-Regulated H3K9 Acetylation on Lipid Accumulation Induced by Homocysteine in Foam Cells. J. Cell. Biochem. 2017, 118 (12), 4617-4627. https://doi.org/10.1002/jcb.2612628485501.

[146] Marques-Rocha, J. L.; Milagro, F. I.; Mansego, M. L.; Zulet, M. A.; Bressan, J.; Martínez, J. A. Expression of Inflammation-Related MiRNAs in White Blood Cells from Subjects with Metabolic Syndrome after $8 \mathrm{Wk}$ of Following a Mediterranean Diet-Based Weight Loss Program. Nutrition 2016, 32 (1), 48-55. https://doi.org/10.1016/j.nut.2015.06.00826421388.

[147] Malcomson, F. C.; Willis, N. D.; McCallum, I.; Xie, L.; Lagerwaard, B.; Kelly, S.; Bradburn, D. M.; Belshaw, N. J.; Johnson, I. T.; Mathers, J. C. Non-Digestible Carbohydrates Supplementation Increases MiR-32 Expression in the Healthy Human Colorectal Epithelium: A Randomized Controlled Trial. Mol. Carcinog. 2017, 56 (9), 2104-2111. https://doi.org/10.1002/mc.2266628418082.

[148] Piroddi, M.; Albini, A.; Fabiani, R.; Giovannelli, L.; Luceri, C.; Natella, F.; Rosignoli, P.; Rossi, T.; Taticchi, A.; Servili, M.; et al. Nutrigenomics of Extra-Virgin Olive Oil: A Review. BioFactors 2017, 43 (1), 17-41. https://doi.org/10.1002/biof.131827580701.

[149] Jiang, M.; Sang, X.; Hong, Z. Beyond Nutrients: Food-Derived MicroRNAs Provide Cross-Kingdom Regulation. Bioessays 2012, 34 (4), 280-284. https://doi.org/10.1002/bies.20110018122354805.

[150] Zhang, L.; Hou, D.; Chen, X.; Li, D.; Zhu, L.; Zhang, Y.; Li, J.; Bian, Z.; Liang, X.; Cai, X.; et al. Exogenous Plant MIR168a Specifically Targets Mammalian LDLRAP1: Evidence of Cross-Kingdom Regulation by MicroRNA. Cell Res. 2012, 22 (1), 107-126. https://doi.org/10.1038/cr.2011.15821931358. 
[151] Daimiel, L.; Micó, V.; Valls, R. M.; Pedret, A.; Motilva, M. J.; Rubió, L.; Fitó, M.; Farrás, M.; Covas, M. I.; Solá, R.; et al. Impact of Phenol-Enriched Virgin Olive Oils on the Postprandial Levels of Circulating MicroRNAs Related to Cardiovascular Disease. Mol. Nutr. Food Res. 2020, 64 (15), e2000049. https://doi.org/10.1002/mnfr.20200004932562310.

[152] Picchiarelli, G.; Dupuis, L. Role of RNA Binding Proteins with Prion-like Domains in Muscle and Neuromuscular Diseases. Cell Stress 2020, 4 (4), 76-91. https://doi.org/10.15698/cst2020.04.21732292882.

[153] Albani, D.; Polito, L.; Signorini, A.; Forloni, G. Neuroprotective Properties of Resveratrol in Different Neurodegenerative Disorders. Biofactors 2010, 36 (5), 370-376. https://doi.org/10.1002/biof.11820848560.

[154] Crawford, T. O.; Pardo, C. A. The Neurobiology of Childhood Spinal Muscular Atrophy. Neurobiol. Dis. 1996, 3 (2), 97-110. https://doi.org/10.1006/nbdi.1996.00109173917.

[155] Frugier, T.; Nicole, S.; Cifuentes-Diaz, C.; Melki, J. The Molecular Bases of Spinal Muscular Atrophy. Curr. Opin. Genet. Dev. 2002, 12 (3), 294-298. https://doi.org/10.1016/s0959-437x(02)00301-512076672.

[156] Monani, U. R. Spinal Muscular Atrophy: A Deficiency in a Ubiquitous Protein; a Motor Neuron-Specific Disease. Neuron 2005, 48 (6), 885-896. https://doi.org/10.1016/j.neuron.2005.12.00116364894.

[157] Arnold, W. D.; Burghes, A. H. M. Spinal Muscular Atrophy: Development and Implementation of Potential Treatments. Ann. Neurol. 2013, 74 (3), 348-362. https://doi.org/10.1002/ana.2399523939659.

[158] Pellizzoni, L.; Yong, J.; Dreyfuss, G. Essential Role for the SMN Complex in the Specificity of SnRNP Assembly. Science 2002, 298 (5599), 1775-1779. https://doi.org/10.1126/science.107496212459587.

[159] Carissimi, C.; Saieva, L.; Baccon, J.; Chiarella, P.; Maiolica, A.; Sawyer, A.; Rappsilber, J.; Pellizzoni, L. Gemin8 Is a Novel Component of the Survival Motor Neuron Complex and Functions in Small Nuclear Ribonucleoprotein Assembly. J. Biol. Chem. 2006, 281 (12), 8126-8134. https://doi.org/10.1074/jbc.M51224320016434402.

[160] Rossoll, W.; Jablonka, S.; Andreassi, C.; Kröning, A.-K.; Karle, K.; Monani, U. R.; Sendtner, M. Smn, the Spinal Muscular Atrophy-Determining Gene Product, Modulates Axon Growth and Localization of Beta-Actin MRNA in Growth Cones of Motoneurons. J. Cell Biol. 2003, 163 (4), 801-812. https://doi.org/10.1083/jcb.20030412814623865.

[161] Tadesse, H.; Deschênes-Furry, J.; Boisvenue, S.; Côté, J. KH-Type Splicing Regulatory Protein Interacts with Survival Motor Neuron Protein and Is Misregulated in Spinal Muscular Atrophy. Hum. Mol. Genet. 2008, 17 (4), 506-524. https://doi.org/10.1093/hmg/ddm32717998247.

[162] Glinka, M.; Herrmann, T.; Funk, N.; Havlicek, S.; Rossoll, W.; Winkler, C.; Sendtner, M. The Heterogeneous Nuclear Ribonucleoprotein-R Is Necessary for Axonal Beta-Actin MRNA Translocation in Spinal Motor Neurons. Hum. Mol. Genet. 2010, 19 (10), 1951-1966. https://doi.org/10.1093/hmg/ddq07320167579.

[163] Peter, C. J.; Evans, M.; Thayanithy, V.; Taniguchi-Ishigaki, N.; Bach, I.; Kolpak, A.; Bassell, G. J.; Rossoll, W.; Lorson, C. L.; Bao, Z.-Z.; et al. The COPI Vesicle Complex Binds and Moves with Survival Motor Neuron within Axons. Hum. Mol. Genet. 2011, 20 (9), 1701-1711. https://doi.org/10.1093/hmg/ddr04621300694.

[164] Hubers, L.; Valderrama-Carvajal, H.; Laframboise, J.; Timbers, J.; Sanchez, G.; Côté, J. HuD Interacts with Survival Motor Neuron Protein and Can Rescue Spinal Muscular Atrophy-like Neuronal Defects. Hum. Mol. Genet. 2011, 20 (3), 553-579. https://doi.org/10.1093/hmg/ddq50021088113.

[165] Fallini, C.; Zhang, H.; Su, Y.; Silani, V.; Singer, R. H.; Rossoll, W.; Bassell, G. J. The Survival of Motor Neuron (SMN) Protein Interacts with the MRNA-Binding Protein HuD and Regulates Localization of Poly(A) MRNA in Primary Motor Neuron Axons. J. Neurosci. 2011, 31 (10), 3914-3925. https://doi.org/10.1523/JNEUROSCI.3631-10.201121389246.

[166] Fallini, C.; Rouanet, J. P.; Donlin-Asp, P. G.; Guo, P.; Zhang, H.; Singer, R. H.; Rossoll, W.; Bassell, G. J. Dynamics of Survival of Motor Neuron (SMN) Protein Interaction with the MRNA-Binding Protein IMP1 Facilitates Its Trafficking into Motor Neuron Axons. Dev. Neurobiol. 2014, 74 (3), 319-332. https://doi.org/10.1002/dneu.2211123897586.

[167] Yamazaki, T.; Chen, S.; Yu, Y.; Yan, B.; Haertlein, T. C.; Carrasco, M. A.; Tapia, J. C.; Zhai, B.; Das, R.; Lalancette-Hebert, M.; et al. FUS-SMN Protein Interactions Link the Motor Neuron Diseases ALS and SMA. Cell Rep. 2012, 2 (4), 799-806. https://doi.org/10.1016/j.celrep.2012.08.02523022481.

[168] Rathod, R.; Havlicek, S.; Frank, N.; Blum, R.; Sendtner, M. Laminin Induced Local Axonal Translation of $\beta$ Actin MRNA Is Impaired in SMN-Deficient Motoneurons. Histochem. Cell Biol. 2012, 138 (5), 737-748. https://doi.org/10.1007/s00418-012-0989-122810847.

[169] Hamilton, G.; Gillingwater, T. H. Spinal Muscular Atrophy: Going beyond the Motor Neuron. Trends Mol. Med. 2013, 19 (1), 40-50. https://doi.org/10.1016/j.molmed.2012.11.00223228902.

[170] Usha, S.; Johnson, I. M.; Malathi, R. Interaction of Resveratrol and Genistein with Nucleic Acids. J. Biochem. Mol. Biol. 2005, 38 (2), 198-205. https://doi.org/10.5483/bmbrep.2005.38.2.19815826497.

[171] Sakla, M. S.; Lorson, C. L. Induction of Full-Length Survival Motor Neuron by Polyphenol Botanical Compounds. Hum. Genet. 2008, 122 (6), 635-643. https://doi.org/10.1007/s00439-007-0441-017962980.

[172] Markus, M. A.; Marques, F. Z.; Morris, B. J. Resveratrol, by Modulating RNA Processing Factor Levels, Can Influence the Alternative Splicing of Pre-MRNAs. PLoS One 2011, 6 (12), e28926. https://doi.org/10.1371/journal.pone.002892622174926.

[173] Cleveland, D. W.; Rothstein, J. D. From Charcot to Lou Gehrig: Deciphering Selective Motor Neuron Death in 
ALS. Nat. Rev. Neurosci. 2001, 2 (11), 806-819. https://doi.org/10.1038/3509756511715057.

[174] Brown, R. H.; Al-Chalabi, A. Amyotrophic Lateral Sclerosis. N. Engl. J. Med. 2017, 377 (2), $162-172$. https://doi.org/10.1056/NEJMra160347128700839.

[175] Valko, K.; Ciesla, L. Amyotrophic Lateral Sclerosis. Prog. Med. Chem. 2019, 58, 63-117. https://doi.org/10.1016/bs.pmch.2018.12.00130879475.

[176] Al-Chalabi, A.; Hardiman, O. The Epidemiology of ALS: A Conspiracy of Genes, Environment and Time. Nat. Rev. Neurol. 2013, 9 (11), 617-628. https://doi.org/10.1038/nrneurol.2013.20324126629.

[177] D’Amico, E.; Pasmantier, M.; Lee, Y.-W.; Weimer, L.; Mitsumoto, H. Clinical Evolution of Pure Upper Motor Neuron Disease/Dysfunction (PUMMD). Muscle Nerve 2013, 47 (1), 28-32. https://doi.org/10.1002/mus.2349623169452.

[178] Gowland, A.; Opie-Martin, S.; Scott, K. M.; Jones, A. R.; Mehta, P. R.; Batts, C. J.; Ellis, C. M.; Leigh, P. N.; Shaw, C. E.; Sreedharan, J.; et al. Predicting the Future of ALS: The Impact of Demographic Change and Potential New Treatments on the Prevalence of ALS in the United Kingdom, 2020-2116. Amyotroph. Lateral Scler. Frontotemporal Degener. 2019, 20 (3-4), 264-274. https://doi.org/10.1080/21678421.2019.158762930961394.

[179] Sferrazza Papa, G. F.; Pellegrino, G. M.; Shaikh, H.; Lax, A.; Lorini, L.; Corbo, M. Respiratory Muscle Testing in Amyotrophic Lateral Sclerosis: A Practical Approach. Minerva Med. 2018, 109 (6 Suppl 1), 11-19. https://doi.org/10.23736/S0026-4806.18.05920-730642145.

[180] Strandberg-Larsen, K.; Poulsen, G.; Bech, B. H.; Chatzi, L.; Cordier, S.; Dale, M. T. G.; Fernandez, M.; Henriksen, T. B.; Jaddoe, V. W.; Kogevinas, M.; et al. Association of Light-to-Moderate Alcohol Drinking in Pregnancy with Preterm Birth and Birth Weight: Elucidating Bias by Pooling Data from Nine European Cohorts. Eur. J. Epidemiol. 2017, 32 (9), 751-764. https://doi.org/10.1007/s10654-017-0323-229027084.

[181] Andersen, P. M.; Borasio, G. D.; Dengler, R.; Hardiman, O.; Kollewe, K.; Leigh, P. N.; Pradat, P.-F.; Silani, V.; Tomik, B. Good Practice in the Management of Amyotrophic Lateral Sclerosis: Clinical Guidelines. An Evidence-Based Review with Good Practice Points. EALSC Working Group. Amyotroph. lateral Scler. Off. Publ. World Fed. Neurol. Res. Gr. Mot. Neuron Dis. 2007, 8 (4), 195-213. https://doi.org/10.1080/1748296070126237617653917.

[182] Gordon, P. H. The Murky Path to Drug Discovery in ALS Becomes Clearer. The Lancet. Neurology. England November 2013, pp 1037-1038. https://doi.org/10.1016/S1474-4422(13)70224-224067399.

[183] Coan, G.; Mitchell, C. S. An Assessment of Possible Neuropathology and Clinical Relationships in 46 Sporadic Amyotrophic Lateral Sclerosis Patient Autopsies. Neurodegener. Dis. 2015, 15 (5), 301-312. https://doi.org/10.1159/00043358126183171.

[184] Wier, C. G.; Crum, A. E.; Reynolds, A. B.; Iyer, C. C.; Chugh, D.; Palettas, M. S.; Heilman, P. L.; Kline, D. M.; Arnold, W. D.; Kolb, S. J. Muscle Contractility Dysfunction Precedes Loss of Motor Unit Connectivity in SOD1(G93A) Mice. Muscle Nerve 2019, 59 (2), 254-262. https://doi.org/10.1002/mus.2636530370671.

[185] Sinaki, M.; Mulder, D. W. Amyotrophic Lateral Sclerosis: Relationship between Serum Creatine Kinase Level and Patient Survival. Arch. Phys. Med. Rehabil. 1986, 67 (3), 169-171. https://doi.org/10.1016/00039993(86)90064-x3954579.

[186] Mitchell, J. D.; Wokke, J. H. J.; Borasio, G. D. Recombinant Human Insulin-like Growth Factor I (RhIGF-I) for Amyotrophic Lateral Sclerosis/Motor Neuron Disease. Cochrane database Syst. Rev. 2007, No. 4, CD002064. https://doi.org/10.1002/14651858.CD002064.pub217943766.

[187] Vijayakumar, U. G.; Milla, V.; Cynthia Stafford, M. Y.; Bjourson, A. J.; Duddy, W.; Duguez, S. M.-R. A Systematic Review of Suggested Molecular Strata, Biomarkers and Their Tissue Sources in ALS. Front. Neurol. 2019, 10, 400. https://doi.org/10.3389/fneur.2019.0040031139131.

[188] Chia, R.; Chiò, A.; Traynor, B. J. Novel Genes Associated with Amyotrophic Lateral Sclerosis: Diagnostic and Clinical Implications. Lancet. Neurol. 2018, 17 (1), 94-102. https://doi.org/10.1016/S1474-4422(17)30401529154141.

[189] Gois, A. M.; Mendonça, D. M. F.; Freire, M. A. M.; Santos, J. R. IN VITRO AND IN VIVO MODELS OF AMYOTROPHIC LATERAL SCLEROSIS: AN UPDATED OVERVIEW. Brain Res. Bull. 2020, 159, $32-43$. https://doi.org/10.1016/j.brainresbull.2020.03.01232247802.

[190] Azuma, Y.; Mizuta, I.; Tokuda, T.; Mizuno, T. Amyotrophic Lateral Sclerosis Model. Adv. Exp. Med. Biol. 2018, 1076, 79-95. https://doi.org/10.1007/978-981-13-0529-0_629951816.

[191] Pasinelli, P.; Brown, R. H. Molecular Biology of Amyotrophic Lateral Sclerosis: Insights from Genetics. Nat. Rev. Neurosci. 2006, 7 (9), 710-723. https://doi.org/10.1038/nrn197116924260.

[192] Boillée, S.; Vande Velde, C.; Cleveland, D. W. ALS: A Disease of Motor Neurons and Their Nonneuronal Neighbors. Neuron 2006, 52 (1), 39-59. https://doi.org/10.1016/j.neuron.2006.09.01817015226.

[193] Karch, C. M.; Prudencio, M.; Winkler, D. D.; Hart, P. J.; Borchelt, D. R. Role of Mutant SOD1 Disulfide Oxidation and Aggregation in the Pathogenesis of Familial ALS. Proc. Natl. Acad. Sci. U. S. A. 2009, 106 (19), 7774-7779. https://doi.org/10.1073/pnas.090250510619416874.

[194] Blokhuis, A. M.; Groen, E. J. N.; Koppers, M.; van den Berg, L. H.; Pasterkamp, R. J. Protein Aggregation in Amyotrophic Lateral Sclerosis. Acta Neuropathol. 2013, 125 (6), 777-794. https://doi.org/10.1007/s00401-0131125-623673820. 
[195] Gao, F.-B.; Almeida, S.; Lopez-Gonzalez, R. Dysregulated Molecular Pathways in Amyotrophic Lateral Sclerosis-Frontotemporal Dementia Spectrum Disorder. EMBO J. 2017, 36 (20), 2931-2950. https://doi.org/10.15252/embj.20179756828916614.

[196] Miller, R. G.; Mitchell, J. D.; Moore, D. H. Riluzole for Amyotrophic Lateral Sclerosis (ALS)/Motor Neuron Disease (MND). Cochrane database Syst. Rev. 2012, 2012 (3), CD001447. https://doi.org/10.1002/14651858.CD001447.pub322419278.

[197] Rothstein, J. D. Edaravone: A New Drug Approved for ALS. Cell 2017, 171 (4), 725. https://doi.org/10.1016/j.cell.2017.10.01129100067.

[198] Mancuso, R.; del Valle, J.; Modol, L.; Martinez, A.; Granado-Serrano, A. B.; Ramirez-Núñez, O.; Pallás, M.; Portero-Otin, M.; Osta, R.; Navarro, X. Resveratrol Improves Motoneuron Function and Extends Survival in SOD1G93A ALS Mice. Neurotherapeutics 2014, 11 (2), 419-432. https://doi.org/10.1007/s13311-013-0253y24414863.

[199] Mancuso, R.; Del Valle, J.; Morell, M.; Pallás, M.; Osta, R.; Navarro, X. Lack of Synergistic Effect of Resveratrol and Sigma-1 Receptor Agonist (PRE-084) in SOD1G ${ }^{93}$ A ALS Mice: Overlapping Effects or Limited Therapeutic Opportunity? Orphanet J. Rare Dis. 2014, 9, 78. https://doi.org/10.1186/1750-1172-97824885036.

[200] Julien, J.-P. ALS: Astrocytes Move in as Deadly Neighbors. Nature neuroscience. United States May 2007, pp 535-537. https://doi.org/10.1038/nn0507-53517453052.

[201] Srinivasan, E.; Rajasekaran, R. Quantum Chemical and Molecular Mechanics Studies on the Assessment of Interactions between Resveratrol and Mutant SOD1 (G93A) Protein. J. Comput. Aided. Mol. Des. 2018, 32 (12), 1347-1361. https://doi.org/10.1007/s10822-018-0175-130368622.

[202] Laudati, G.; Mascolo, L.; Guida, N.; Sirabella, R.; Pizzorusso, V.; Bruzzaniti, S.; Serani, A.; Di Renzo, G.; Canzoniero, L. M. T.; Formisano, L. Resveratrol Treatment Reduces the Vulnerability of SH-SY5Y Cells and Cortical Neurons Overexpressing SOD1-G93A to Thimerosal Toxicity through SIRT1/DREAM/PDYN Pathway. Neurotoxicology 2019, 71, 6-15. https://doi.org/10.1016/j.neuro.2018.11.00930503815.

[203] Wang, J.; Zhang, Y.; Tang, L.; Zhang, N.; Fan, D. Protective Effects of Resveratrol through the Up-Regulation of SIRT1 Expression in the Mutant HSOD1-G93A-Bearing Motor Neuron-like Cell Culture Model of Amyotrophic Lateral Sclerosis. Neurosci. Lett. 2011, 503 (3), 250-255. https://doi.org/10.1016/j.neulet.2011.08.04721896316.

[204] Han, S.; Choi, J. R.; Soon Shin, K.; Kang, S. J. Resveratrol Upregulated Heat Shock Proteins and Extended the Survival of G93A-SOD1 Mice. Brain Res. 2012, 1483, 112-117. https://doi.org/10.1016/j.brainres.2012.09.02223000195.

[205] Kim, E.-J.; Kho, J.-H.; Kang, M.-R.; Um, S.-J. Active Regulator of SIRT1 Cooperates with SIRT1 and Facilitates Suppression of P53 Activity. Mol. Cell 2007, 28 (2), 277-290. https://doi.org/10.1016/j.molcel.2007.08.03017964266.

[206] Yun, Y. C.; Jeong, S. G.; Kim, S. H.; Cho, G. W. Reduced Sirtuin 1/Adenosine Monophosphate-Activated Protein Kinase in Amyotrophic Lateral Sclerosis Patient-Derived Mesenchymal Stem Cells Can Be Restored by Resveratrol. J. Tissue Eng. Regen. Med. 2019, 13 (1), 110-115. https://doi.org/10.1002/term.277630479062.

[207] de Almeida, L. M. V.; Piñeiro, C. C.; Leite, M. C.; Brolese, G.; Tramontina, F.; Feoli, A. M.; Gottfried, C.; Gonçalves, C.-A. Resveratrol Increases Glutamate Uptake, Glutathione Content, and S100B Secretion in Cortical Astrocyte Cultures. Cell. Mol. Neurobiol. 2007, 27 (5), 661-668. https://doi.org/10.1007/s10571-0079152-217554623.

[208] Yáñez, M.; Galán, L.; Matías-Guiu, J.; Vela, A.; Guerrero, A.; García, A. G. CSF from Amyotrophic Lateral Sclerosis Patients Produces Glutamate Independent Death of Rat Motor Brain Cortical Neurons: Protection by Resveratrol but Not Riluzole. Brain Res. 2011, 1423, 77-86. https://doi.org/10.1016/j.brainres.2011.09.02521983205.

[209] Davies, K. E.; Nowak, K. J. Molecular Mechanisms of Muscular Dystrophies: Old and New Players. Nat. Rev. Mol. Cell Biol. 2006, 7 (10), 762-773. https://doi.org/10.1038/nrm202416971897.

[210] Barresi, R.; Campbell, K. P. Dystroglycan: From Biosynthesis to Pathogenesis of Human Disease. J. Cell Sci. 2006, 119 (Pt 2), 199-207. https://doi.org/10.1242/jcs.0281416410545.

[211] Laval, S. H.; Bushby, K. M. D. Limb-Girdle Muscular Dystrophies--from Genetics to Molecular Pathology. Neuropathol. Appl. Neurobiol. 2004, 30 (2), 91-105. https://doi.org/10.1111/j.13652990.2004.00555.x15043707.

[212] Bladen, C. L.; Salgado, D.; Monges, S.; Foncuberta, M. E.; Kekou, K.; Kosma, K.; Dawkins, H.; Lamont, L.; Roy, A. J.; Chamova, T.; et al. The TREAT-NMD DMD Global Database: Analysis of More than 7,000 Duchenne Muscular Dystrophy Mutations. Hum. Mutat. 2015, 36 (4), 395-402. https://doi.org/10.1002/humu.2275825604253.

[213] Guiraud, S.; Aartsma-Rus, A.; Vieira, N. M.; Davies, K. E.; van Ommen, G.-J. B.; Kunkel, L. M. The Pathogenesis and Therapy of Muscular Dystrophies. Annu. Rev. Genomics Hum. Genet. 2015, 16, $281-308$. https://doi.org/10.1146/annurev-genom-090314-02500326048046.

[214] England, S. B.; Nicholson, L. V; Johnson, M. A.; Forrest, S. M.; Love, D. R.; Zubrzycka-Gaarn, E. E.; Bulman, D. E.; Harris, J. B.; Davies, K. E. Very Mild Muscular Dystrophy Associated with the Deletion of $46 \%$ of 
Dystrophin. Nature 1990, 343 (6254), 180-182. https://doi.org/10.1038/343180a02404210.

[215] Bach, J. R.; O’Brien, J.; Krotenberg, R.; Alba, A. S. Management of End Stage Respiratory Failure in Duchenne Muscular Dystrophy. Muscle Nerve 1987, 10 (2), 177-182. https://doi.org/10.1002/mus.8801002123547120.

[216] Crusius, K.; Finster, S.; McClary, J.; Xia, W.; Larsen, B.; Schneider, D.; Lu, H. T.; Biancalana, S.; Xuan, J. A.; Newton, A.; et al. Tab2, a Novel Recombinant Polypeptide Tag Offering Sensitive and Specific Protein Detection and Reliable Affinity Purification. Gene 2006, 380 (2), 111-119. https://doi.org/10.1016/j.gene.2006.05.02716879932.

[217] Kamdar, F.; Garry, D. J. Dystrophin-Deficient Cardiomyopathy. J. Am. Coll. Cardiol. 2016, 67 (21), $2533-$ 2546. https://doi.org/10.1016/j.jacc.2016.02.08127230049.

[218] Sun, C.; Shen, L.; Zhang, Z.; Xie, X. Therapeutic Strategies for Duchenne Muscular Dystrophy: An Update. Genes (Basel). 2020, 11 (8). https://doi.org/10.3390/genes1108083732717791.

[219] Monaco, A. P.; Neve, R. L.; Colletti-Feener, C.; Bertelson, C. J.; Kurnit, D. M.; Kunkel, L. M. Isolation of Candidate CDNAs for Portions of the Duchenne Muscular Dystrophy Gene. Nature 1986, 323 (6089), 646-650. https://doi.org/10.1038/323646a03773991.

[220] Guiraud, S.; Davies, K. E. Pharmacological Advances for Treatment in Duchenne Muscular Dystrophy. Curr. Opin. Pharmacol. 2017, 34, 36-48. https://doi.org/10.1016/j.coph.2017.04.00228486179.

[221] De Arcangelis, V.; Strimpakos, G.; Gabanella, F.; Corbi, N.; Luvisetto, S.; Magrelli, A.; Onori, A.; Passananti, C.; Pisani, C.; Rome, S.; et al. Pathways Implicated in Tadalafil Amelioration of Duchenne Muscular Dystrophy. J. Cell. Physiol. 2016, 231 (1), 224-232. https://doi.org/10.1002/jcp.2507526097015.

[222] Dudley, R. W. R.; Khairallah, M.; Mohammed, S.; Lands, L.; Des Rosiers, C.; Petrof, B. J. Dynamic Responses of the Glutathione System to Acute Oxidative Stress in Dystrophic Mouse (Mdx) Muscles. Am. J. Physiol. Regul. Integr. Comp. Physiol. 2006, 291 (3), R704-10. https://doi.org/10.1152/ajpregu.00031.200616614063.

[223] Renjini, R.; Gayathri, N.; Nalini, A.; Srinivas Bharath, M. M. Oxidative Damage in Muscular Dystrophy Correlates with the Severity of the Pathology: Role of Glutathione Metabolism. Neurochem. Res. 2012, 37 (4), 885-898. https://doi.org/10.1007/s11064-011-0683-z22219131.

[224] Petrillo, S.; Pelosi, L.; Piemonte, F.; Travaglini, L.; Forcina, L.; Catteruccia, M.; Petrini, S.; Verardo, M.; D'Amico, A.; Musarò, A.; et al. Oxidative Stress in Duchenne Muscular Dystrophy: Focus on the NRF2 Redox Pathway. Hum. Mol. Genet. 2017, 26 (14), 2781-2790. https://doi.org/10.1093/hmg/ddx17328472288.

[225] Kuno, A.; Tanno, M.; Horio, Y. The Effects of Resveratrol and SIRT1 Activation on Dystrophic Cardiomyopathy. Ann. N. Y. Acad. Sci. 2015, 1348 (1), 46-54. https://doi.org/10.1111/nyas.1281226109180.

[226] Hori, Y. S.; Kuno, A.; Hosoda, R.; Tanno, M.; Miura, T.; Shimamoto, K.; Horio, Y. Resveratrol Ameliorates Muscular Pathology in the Dystrophic Mdx Mouse, a Model for Duchenne Muscular Dystrophy. J. Pharmacol. Exp. Ther. 2011, 338 (3), 784-794. https://doi.org/10.1124/jpet.111.18321021652783.

[227] Howitz, K. T.; Bitterman, K. J.; Cohen, H. Y.; Lamming, D. W.; Lavu, S.; Wood, J. G.; Zipkin, R. E.; Chung, P.; Kisielewski, A.; Zhang, L.-L.; et al. Small Molecule Activators of Sirtuins Extend Saccharomyces Cerevisiae Lifespan. Nature 2003, 425 (6954), 191-196. https://doi.org/10.1038/nature0196012939617.

[228] Chalkiadaki, A.; Igarashi, M.; Nasamu, A. S.; Knezevic, J.; Guarente, L. Muscle-Specific SIRT1 Gain-ofFunction Increases Slow-Twitch Fibers and Ameliorates Pathophysiology in a Mouse Model of Duchenne Muscular Dystrophy. PLoS Genet. 2014, 10 (7), e1004490. https://doi.org/10.1371/journal.pgen.100449025032964.

[229] Kuno, A.; Hori, Y. S.; Hosoda, R.; Tanno, M.; Miura, T.; Shimamoto, K.; Horio, Y. Resveratrol Improves Cardiomyopathy in Dystrophin-Deficient Mice through SIRT1 Protein-Mediated Modulation of P300 Protein. J. Biol. Chem. 2013, 288 (8), 5963-5972. https://doi.org/10.1074/jbc.M112.39205023297412.

[230] Sebori, R.; Kuno, A.; Hosoda, R.; Hayashi, T.; Horio, Y. Resveratrol Decreases Oxidative Stress by Restoring Mitophagy and Improves the Pathophysiology of Dystrophin-Deficient Mdx Mice. Oxid. Med. Cell. Longev. 2018, 2018, 9179270. https://doi.org/10.1155/2018/917927030510631.

[231] Kuno, A.; Hosoda, R.; Sebori, R.; Hayashi, T.; Sakuragi, H.; Tanabe, M.; Horio, Y. Resveratrol Ameliorates Mitophagy Disturbance and Improves Cardiac Pathophysiology of Dystrophin-Deficient Mdx Mice. Sci. Rep. 2018, 8 (1), 15555. https://doi.org/10.1038/s41598-018-33930-w30348945.

[232] Gordon, B. S.; Delgado Díaz, D. C.; Kostek, M. C. Resveratrol Decreases Inflammation and Increases Utrophin Gene Expression in the Mdx Mouse Model of Duchenne Muscular Dystrophy. Clin. Nutr. 2013, 32 (1), 104 111. https://doi.org/10.1016/j.clnu.2012.06.00322795790. 


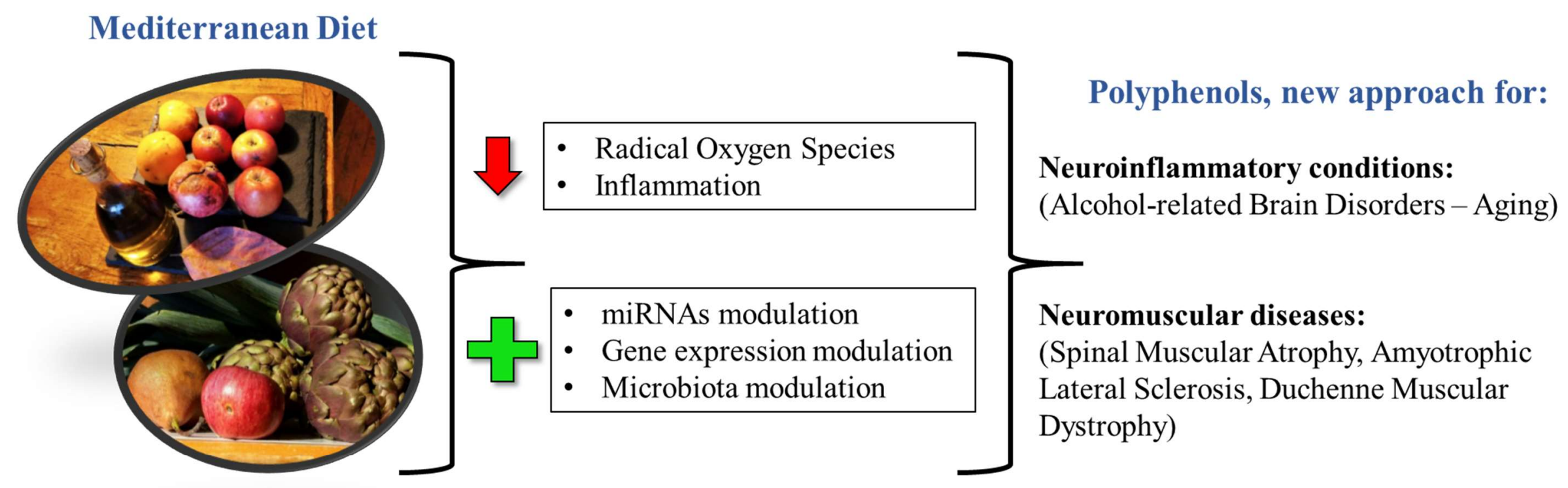

Graphical Abstract 


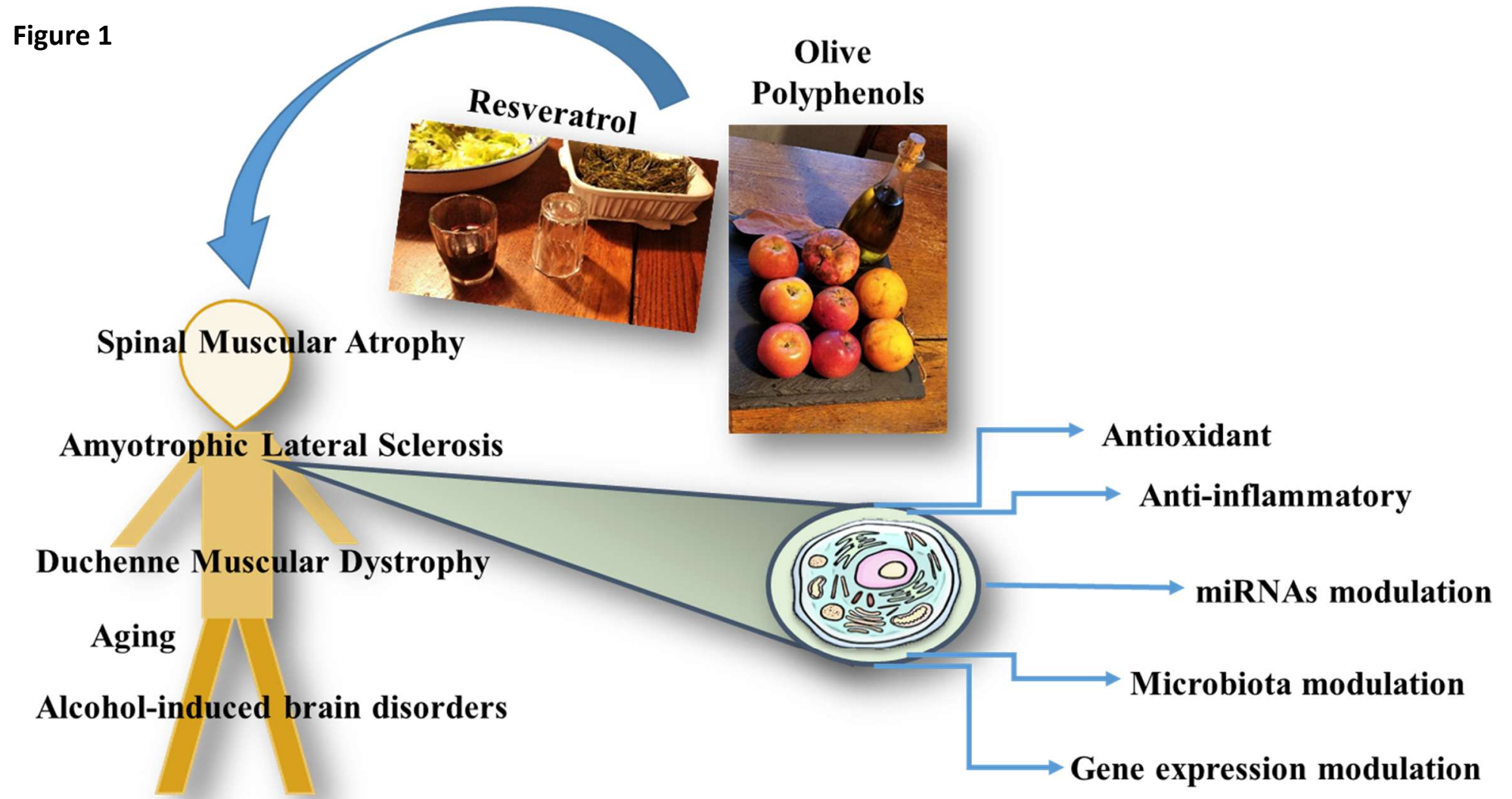

